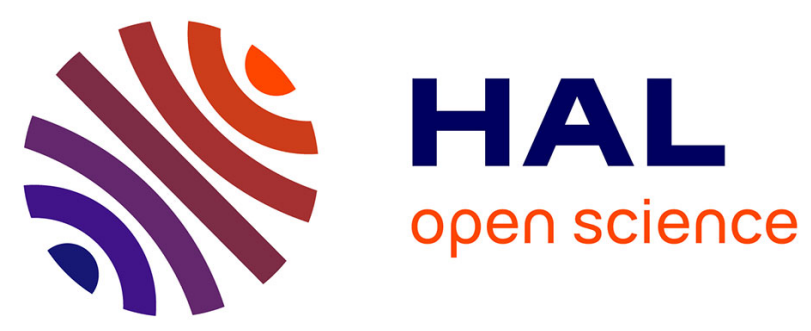

\title{
A global strategy based on experiments and simulations for squeal prediction on industrial railway brakes
} Jean-Jacques Sinou, Andréa Loyer, Olivier Chiello, Guillaume Mogenier, Xavier Lorang, Franck Cocheteux, Selim Bellaj

\section{- To cite this version:}

Jean-Jacques Sinou, Andréa Loyer, Olivier Chiello, Guillaume Mogenier, Xavier Lorang, et al.. A global strategy based on experiments and simulations for squeal prediction on industrial railway brakes. Journal of Sound and Vibration, 2013, 332 (20), pp. 5068-5085. 10.1016/j.jsv.2013.04.008 . hal00855074

\section{HAL Id: hal-00855074 https://hal.science/hal-00855074}

Submitted on 28 Aug 2013

HAL is a multi-disciplinary open access archive for the deposit and dissemination of scientific research documents, whether they are published or not. The documents may come from teaching and research institutions in France or abroad, or from public or private research centers.
L'archive ouverte pluridisciplinaire HAL, est destinée au dépôt et à la diffusion de documents scientifiques de niveau recherche, publiés ou non, émanant des établissements d'enseignement et de recherche français ou étrangers, des laboratoires publics ou privés. 


\title{
A global strategy based on experiments and simulations for squeal prediction on industrial railway brakes
}

\author{
J-J. Sinou ${ }^{a}$, A. Loyer ${ }^{a, b, c}$, O. Chiello ${ }^{c, d}$, G. Mogenier ${ }^{a}$, X. Lorang ${ }^{b}$, F. Cocheteux ${ }^{e}$ and S. Bellaj ${ }^{e}$ \\ ${ }^{a}$ Laboratoire de Tribologie et Dynamique des Systèmes UMR 5513, Ecole Centrale Lyon, 36 avenue Guy de \\ Collongue, 69134 Ecully Cedex, France \\ ${ }^{b}$ SNCF Innovative and Research Department, Physics of Railway System and Passenger Comfort 40 Avenue des \\ Terroirs de France 75611 Paris Cedex 12, France \\ ${ }^{c}$ IFSTTAR, LAE, F-69675 Bron, France \\ ${ }^{d}$ Centre Lyonnais d'Acoustique, Université de Lyon, F-69622 Lyon, France \\ ${ }^{e}$ SNCF Agence d'Essai Ferroviaire, 21 Avenue du Président Allende, 94407 Vitry-Sur-Seine, France
}

\begin{abstract}
This paper presents an overview of recent experimental and numerical investigations on industrial railway brakes. The goal of the present study is to discuss the relevance of the mechanical modeling strategy for squeal prediction. Specific experimental set-ups based on transient and controlled braking tests are designed for this purpose. Measurements are performed on it to investigate the dynamic behavior of $T G V$ squeal noise and its squeal characterization through experiments. It will be demonstrated that it is possible to build consistent and efficient finite element models to simulate squeal events in TGV brake systems. The numerical strategy will be presented, including not only the modeling of the TGV brake system and the stability analysis, but also the transient nonlinear dynamic and computational process based on efficient reduced basis. This complete numerical strategy allows us to perform relevance squeal prediction on industrial railway brakes. This study comes within the scope of a research program AcouFren that is supported by ADEME (Agence De l'Environnement et de la Maîtrise de l'Energie) concerning the reduction of the squeal noise generated by high power railway disc brakes.
\end{abstract}

\section{Introduction}

Friction-induced vibration and noise emanating from railway disc brakes is a source of considerable discomfort and leads to dissatisfaction for the passengers both inside and outside the trains in stations. Research for predicting and removing squeal noise has been regularly performed for many years on industrial railway brakes. This is the case in particular for TGV brake system for which a refined mechanical modeling of the phenomenon was carried out in order to understand the mechanism of squeal generation [1-3]. Despite great progress in the understanding and modeling of brake squeal, there is still considerable progress to provide in order to achieve a comprehensive strategy based on experimental and numerical approaches for squeal prediction on industrial railway brakes.

In the automotive and aeronautic industries the phenomenon of brake squeal is well known because of the noise and vibration produced. Although it has been the subject of many investigations over recent decades [4-7], friction-induced instabilities are still an active field of research in dynamics. Solving potential friction-induced vibration problems requires experimental and theoretical approaches to obtain a better understanding of the phenomenon. A result often discussed is the difficulty in obtaining repeatable experimental tests and correlations with phenomenological lumped parameter models or more sophisticated finite element models. For example, Oberst and Lai proposed to enhance understanding of friction-related noise phenomena by classifying brake squeal mechanisms [8]. They also highlighted the nonlinear character of brake squeal and proposed the use of nonlinear statistical analysis tools to better analyze disc brake squeal in automotive industry [9]. Similarly Sinou et al. [7,10] studied the nonlinear vibration induced by friction in aircraft brakes based on experimental and numerical approaches. Their work showed that the dispersions of the coefficient of friction and of the damping allow the faithful simulation of the dynamical behavior obtained in experimental tests [11]. The studies of Butlin and Woodhouse [12-14] proposed also a discussion 
to quantify the repeatability and uncertainties of experimental results to provide inputs for the error-bound analysis in the numerical squeal prediction.

For industrial system, it is not trivial to reproduce consistently the dynamic behavior of brake systems due to the complexity of the brake components and the difficulty of validating a finite element model. To avoid the difficulty arising from the complexity of experiments on real industrial brake systems, many research groups working on this subject conducted their investigations by combining theory and experiments on simplified experimental rigs [13,15-19]. They demonstrated that disc brake squeal characterization through simplified experimental set-ups is consistent and allows the possibility to build robust models to simulate squeal noise and to undertake a complete understanding of the squeal mechanism and the physics behind

squeal phenomena. For example, Akay et al. [15] deservedly explained that the first step is to be able to provide a model and numerical results consistent with experiments obtained from simplified test rigs. Otherwise numerical models would not be adequate for real industrial brake.

The goal of this study is to present an experimental and numerical analysis of the squeal vibration and prediction on industrial railway brakes. This first part of the paper gives a brief description of the TGV disc brake system and the analysis of experimental data coming from tests on bench in laboratory SNCF. Secondly, the paper focuses on the numerical results provided by a finite element model of the brake including unilateral contact and Coulomb friction at multiple interfaces between disc and pads. A stability analysis of the sliding equilibrium is investigated by performing a complex eigenvalue analysis of the linearized equations (i.e. complex eigenvalue problem). Then a complete dynamic transient analysis (i.e. nonlinear self-excited vibration due to instabilities) is undertaken. More particularly, comparisons with experimental results will be performed in order to judge the relevance of the mechanical modeling strategy for squeal prediction on industrial railway brakes.

\section{Experimental approaches}

\subsection{Motivations}

Experimental investigation of squeal noise for TGV industrial railway systems is nontrivial due to the high complexity of the brakes and the possibility of dispersion of data during experimental tests. As a consequence, it is generally difficult to perform repeatable measurements. Since the squeal problem is not yet completely understood, many studies start by conducting experiments on simplified test rigs [13,15,17]. To avoid the difficulty arising from a realistic braking test (i.e. transient braking test with decrease of the rotational speed of the disc), they proposed to conduct "controlled squeal tests" (i.e. braking test with a constant controlled rotational speed of the disc) to investigate the dynamic behavior of a mechanical system during sliding contact. This choice is based on the assumption that simplifying the experimental protocol is necessary in order to obtain reliable data during experiments of squeal noise. Moreover, this choice of constant speed tests is commonly based on the idea that squeal behavior changes on a much faster time-scale than sliding speed changes. Finally, a common argument against more realistic experiments is that important aspects that can lead to squeal noise are neglected from a modeling point of view. Indeed it is quite difficult to create a finite element model of the brake system with a consistent and significant control of the key parameters such as the pressure distribution between disc and pads, modal damping of the components, contact stiffness, evolution of the friction coefficient, evolution of the rotating speed of the disc, etc.

So the motivation and the goal of this section "Experimental approaches" is to present a complete experimental procedure in order to propose brake squeal characterization and understanding of squeal noise on a real TGV industrial railway brake systems with realistic braking tests (i.e. experimental set-ups with a decrease of the rotational speed of the disc). The main findings obtained through experimental investigations are presented and discussed to provide a complete and rigorous view of squeal noise in TGV brake system. The ultimate goal is to validate, via comparisons of experimental tests with various operating conditions (more particularly by taking into account the two possibilities of variable or constant rotating speed of the disc), the possibility of simulating squeal events via a numerical analysis which takes into account only a 


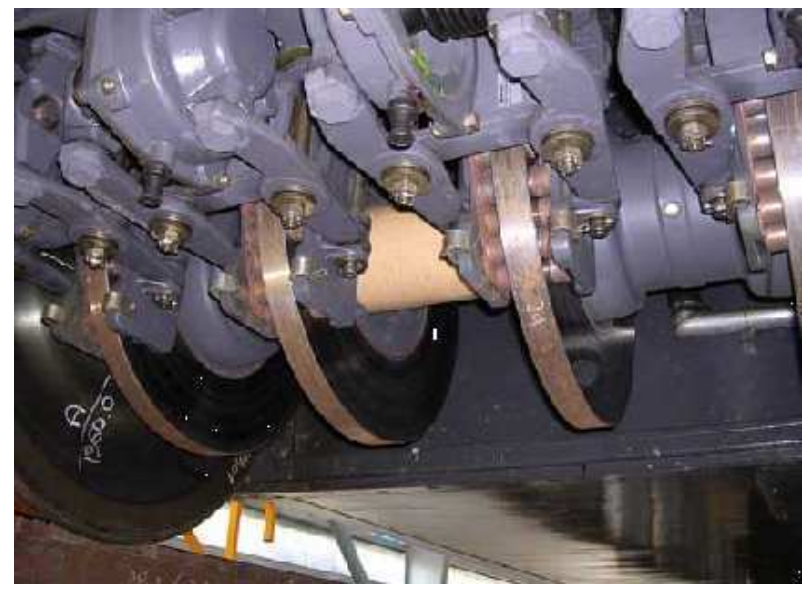

(a)

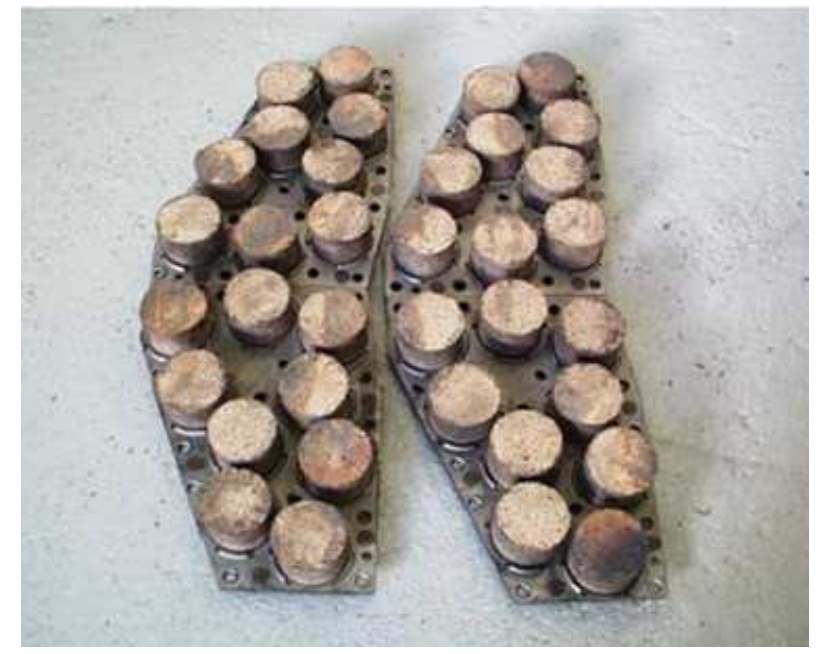

(b)

Figure 1: TGV brake system (a) TGV bogie (b) part of a brake pad

constant rotating speed of the disc. This fact will be explained and argued in detail in the Section 2.4.

\subsection{Description of the TGV brake system and experimental set-up}

The disc-brake system is composed of four discs on each wheels axle and sliding bodies that are constituted of two symmetric lining plates with cylindrical pads (18 pad for each side), as illustrated in Figures 1 . The brakes are activated by the pneumatic system pressure and slow down rotation of the wheels by the friction caused by pressing brake pads against brake discs.

The evaluation of the squeal prediction and the dynamical behavior of the TGV brake system under working conditions are performed with the help of dynamic tests on bench that is located at SNCF Agence d'Essai Ferroviaire. The spectrum of brake squeal and transient vibrations are obtained via the experimental measurements. For this, the TGV brake system is fully instrumented with accelerometers on the stationary part, as indicated in Figure 2. This experimental test rig corresponds to one of the four discs that have been previously shown in Figure 1(a). Due to the fact that coupling between the four discs of the whole disc-brake system is insignificant, this test rig is able to reproduce the squeal phenomena of TGV brake system in service.

Vibration measurements of the normal velocity of the disc are performed by using a laser vibrometer. Moreover, a microphone recording is mounted close to the disc as indicated in Figure 2. Operational parameters such as the normal load, the rotating speed of the disc, the ambient temperature close to each component of the TGV brake system can be measured and controlled during experiments. This allows us to attempt to explain or to correlate any sudden changes in squeal mechanisms and the dynamic behavior of the TGV brake system that occurred with external or internal environmental factors.

To have a more precise estimation of the range and variability of vibration instabilities at the origin of disc brake squeal, a series of tests with the fully instrumented TGV brake system are performed for different operating conditions. Effects of the normal load, the rotational speed of the disc, the clockwise or anticlockwise directions for the disc running are investigated. Moreover, experimental tests are divided into two main categories:

- experiments with an evolution of the rotational speed of the disc: these tests are called "transient braking tests" and correspond to real braking tests,

- experiments with a controlled steady rotational speed (i.e. dynamic fluctuations in rotational speed are not significant): these tests are called "controlled braking tests". 
In the present study, the Continuous Wavelet Transform (CWT) [20] is used to study the time-history responses of the TGV brake system. So, a brief basic theory of the wavelet analysis that transforms a signal into wavelets that are well localized both in frequency and time is presented in this part of the paper. Considering a function $f(t)$, the associated Continuous Wavelet Transform (CWT) corresponds to a wavelet transform given by

$$
W(a, b)=\int_{-\infty}^{+\infty} f(t) \psi_{a, b}^{*}(t) \mathrm{d} t \quad \text { where } \quad \psi_{a, b}(t)=\frac{1}{\sqrt{a}} \psi\left(\frac{t-b}{a}\right)
$$

where $a$ and $b$ define the scale parameter and the time translation factor, respectively. The asterisk $\psi_{a, b}^{*}$ indicates the complex conjugate of $\psi_{a, b}$ that are the daughter wavelets (i.e. the dilated and shifted versions of the "'mother"' wavelet $\psi$ that is continuous in both time and frequency). The mother wavelet must satisfy an admissibility criterion in order to get a stably invertible transform.

The success of the reconstruction depends on the constant $C_{\psi}$ called the admissibility constant that can be defined by

$$
C_{\psi}=\int_{-\infty}^{+\infty} \frac{|\hat{\psi}(\omega)|^{2}}{|\omega|} \mathrm{d} \omega
$$

where $\hat{\psi}$ is the Fourier transform of $\psi$ (i.e. $\hat{\psi}=\int_{-\infty}^{+\infty} f(t) \mathrm{e}^{\mathrm{i} \omega t} \mathrm{~d} t$ ). For a successful inverse transform, the following admissibility condition has to be satisfied $0<C_{\psi}<+\infty$. It can be shown that the admissibility condition implies that $\hat{\psi}(0)=\int_{-\infty}^{+\infty} \psi(t) \mathrm{d} t=0$.

For a function $f(t)$ represented by $N$ sampled data points with uniform time step $\delta t$ between each point, the Continuous Wavelet Transform of equation (1) is a convolution of the data sequence $f\left(n^{\prime}\right)$ (with $\left.n^{\prime}=1, \ldots, N\right)$ with a scaled and normalized wavelet

$$
C(a, n)=\sum_{n^{\prime}=0}^{N-1} f\left(n^{\prime}\right) \sqrt{\frac{\delta t}{a}} \psi_{0}^{*}\left(\frac{\left(n^{\prime}-n\right) \delta t}{a}\right)
$$

where $\delta t$ and $n$ correspond to the sampling interval and the localized time index.

Many types of wavelets have been developed. In this paper, the Morlet wavelet that is one of the most widely used mother wavelets (quite well localized in both time and frequency space) is chosen. It is defined as following in the time domain: $\psi_{0}(\eta)=\pi^{-\frac{1}{4}} \mathrm{e}^{\mathrm{i} m \eta} \mathrm{e}^{-\frac{\eta^{2}}{2}}$ where $m$ is the wavenumber and $\eta$ is non-dimensional time parameter. The wavelet function contains unit energy at every scale due to the normalization of the mother wavelet. Then, the wavelet power is defined as $|C(a, n)|^{2}$.

\subsection{Transient braking tests}

In this section, experiments with an evolution of the rotational speed of the disc (i.e. experimental tests called "transient braking tests") are presented and discussed. For the reader comprehension, we recall that these tests correspond to the actual operating conditions of a TGV brake system in service: the TGV disc is brought up to speed, and then pressure is introduced to activate the brake. The test ends when the TGV disc stops.

More particularly, experiments are undertaken into six main categories:

- effects of the variation of the rotational speed before braking system: $25 \mathrm{~km} / \mathrm{h}$ and $60 \mathrm{~km} / \mathrm{h}$,

- effects of the rotational direction of the disc: clockwise or anticlockwise directions defined by Rot + and Rot-, respectively,

- effects of the compression force $(8 \mathrm{kN}$ and $15 \mathrm{kN})$.

These configurations have been chosen due to the fact that they represent the operating conditions for the specification of TGV brake system in regard to squeal noise. The upper figures 3 illustrate the evolutions of the rotational speed of the disc during braking tests for each initial operating conditions $(25 \mathrm{~km} / \mathrm{h}$ and $60 \mathrm{~km} / \mathrm{h}$ with the two compression forces $8 \mathrm{kN}$ or $15 \mathrm{kN}$ ). 


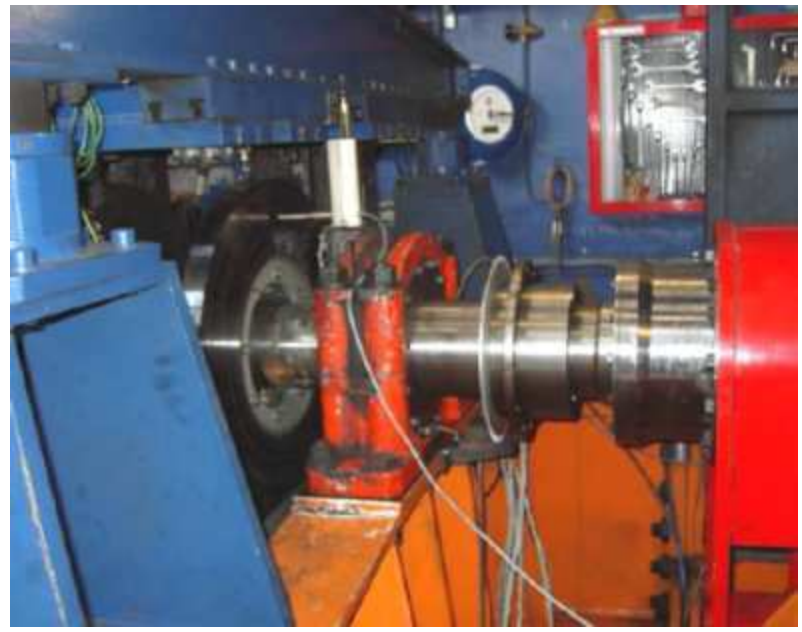

(a)

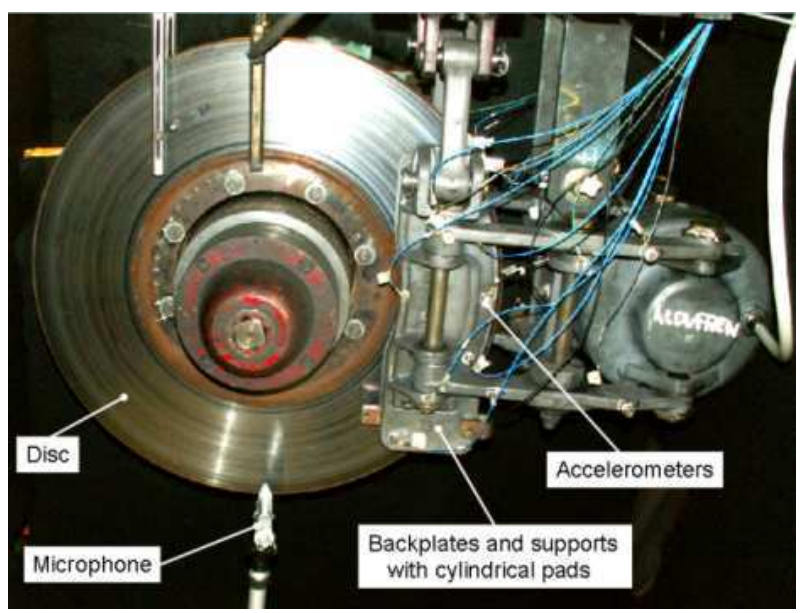

(b)

Figure 2: Dynamic tests for TGV brake squeal (a) test bench (b) instrumented TGV brake system

Figures 4 show the transient nonlinear responses (velocity of a normal point on the disc) and the wavelet power spectrum for vibrometer's measurement. The velocity response appears to be very complicated. First of all, it can be seen that the velocity response increases between $t=[2.5 ; 3.2] \mathrm{s}$. Secondly, a small decrease is observed between $t=[3.2 ; 3.8] \mathrm{s}$. Finally, a small increase of the velocity signal is shown for $t=[3.8 ; 10] \mathrm{s}$. The associated wavelet power spectrum during the transient oscillations is given in the bottom Figure 4. Several frequency contributions are observed during all the transient oscillations. More details will be given in the next paragraph of this section about the squeal signature and the vibrational frequency components of squeal noise. Finally, this first observation illustrates the fact that the transient self-excited vibrations have to be examined in detail in order to understand TGV squeal noise.

Then, experimental results (microphone measurement) for four operating conditions $(15 \mathrm{kN}-60 \mathrm{~km} / \mathrm{h}$, $15 \mathrm{kN}-25 \mathrm{~km} / \mathrm{h}, 8 \mathrm{kN}-60 \mathrm{~km} / \mathrm{h}$ and $8 \mathrm{kN}-25 \mathrm{~km} / \mathrm{h}$ with a positive rotation Rot + ) are given in Figures 3. The repeatability of experiments is investigated by performing three identical tests for each deterministic operating condition. These three tests were performed consecutively respecting a certain time between each test to afford to have the same operating conditions (such as temperature). For each test, the constant compression force is applied during the time window of the plots. So the onset of squeal is triggered by bringing the pads into contact.

Comparing Figures 4 and 3(b), it appears that many of the vibration frequencies that have been obtained with the vibrometer measurement coincide with the noise frequencies that have been observed with the microphone measurement. So it can be assumed that some audible squeal can be considered to result from displacement normal to the disc. So, in the following part of the study (Section 3.3 "Nonlinear selfexcited vibrations and comparison with experiments"), the prediction of squeal noise will be performed by comparing numerical tests and experiments on vibration measurements (velocity of a normal point on the disc for example).

Table 1 gives the simultaneous presence of frequencies in a single squeal occurrence for each operating condition. The symbol $\times$ indicates the presence of the frequency for a given test. Moreover, the variation (i.e. \pm bounds on the squeal frequencies) is within and between tests and the frequencies content is given for the whole transient tests. It appears that the response of the TGV brake system and the associated frequency content are similar between three tests when a series of deterministic tests is performed in the same operating conditions. Tests allow identifying two main complex nonlinear phenomena for TGV brake squeal. The first identified behavior is illustrated in Figures $3(\mathrm{a})$ and (b) (for $15 \mathrm{kN}-60 \mathrm{~km} / \mathrm{h}$ and $15 \mathrm{kN}$ $25 \mathrm{~km} / \mathrm{h}$ ). The second one is given in Figures $3(\mathrm{c})$ and (d) (for $8 \mathrm{kN}-60 \mathrm{~km} / \mathrm{h}$ and $8 \mathrm{kN}-25 \mathrm{~km} / \mathrm{h}$ ). Even if the nonlinear transient response and the associated CWT are not identical, the frequency content of TGV 

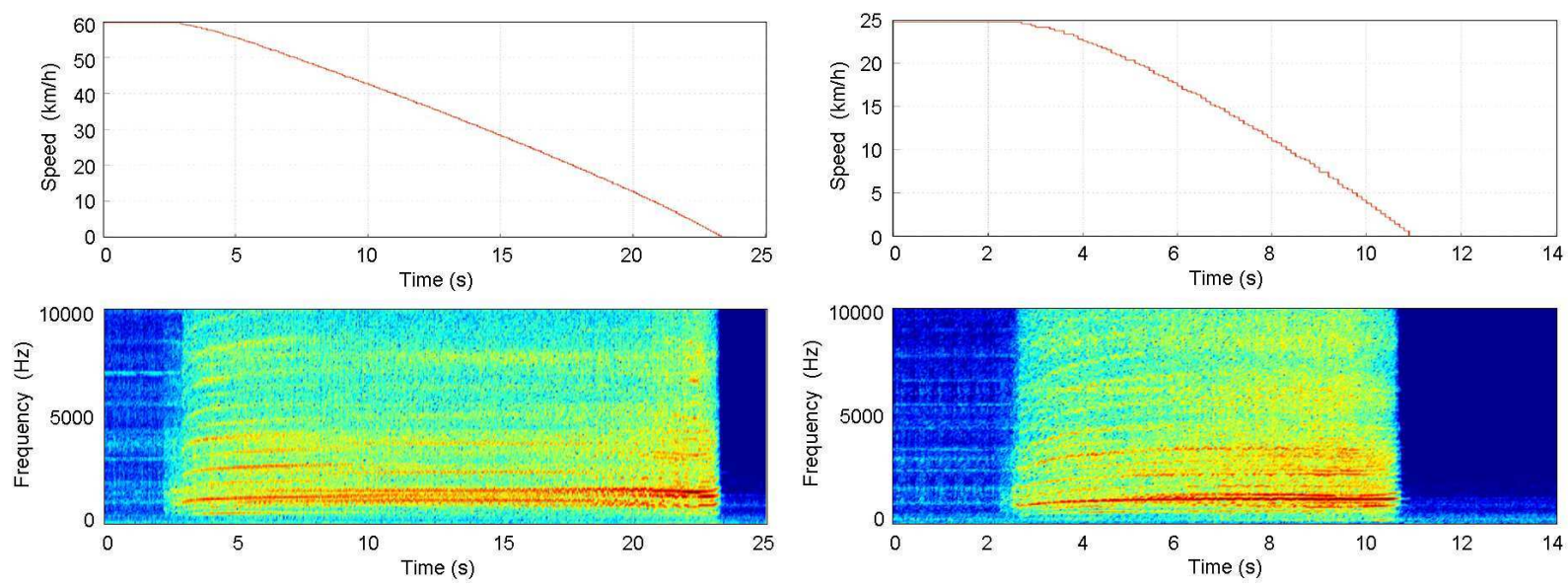

(a)

(b)
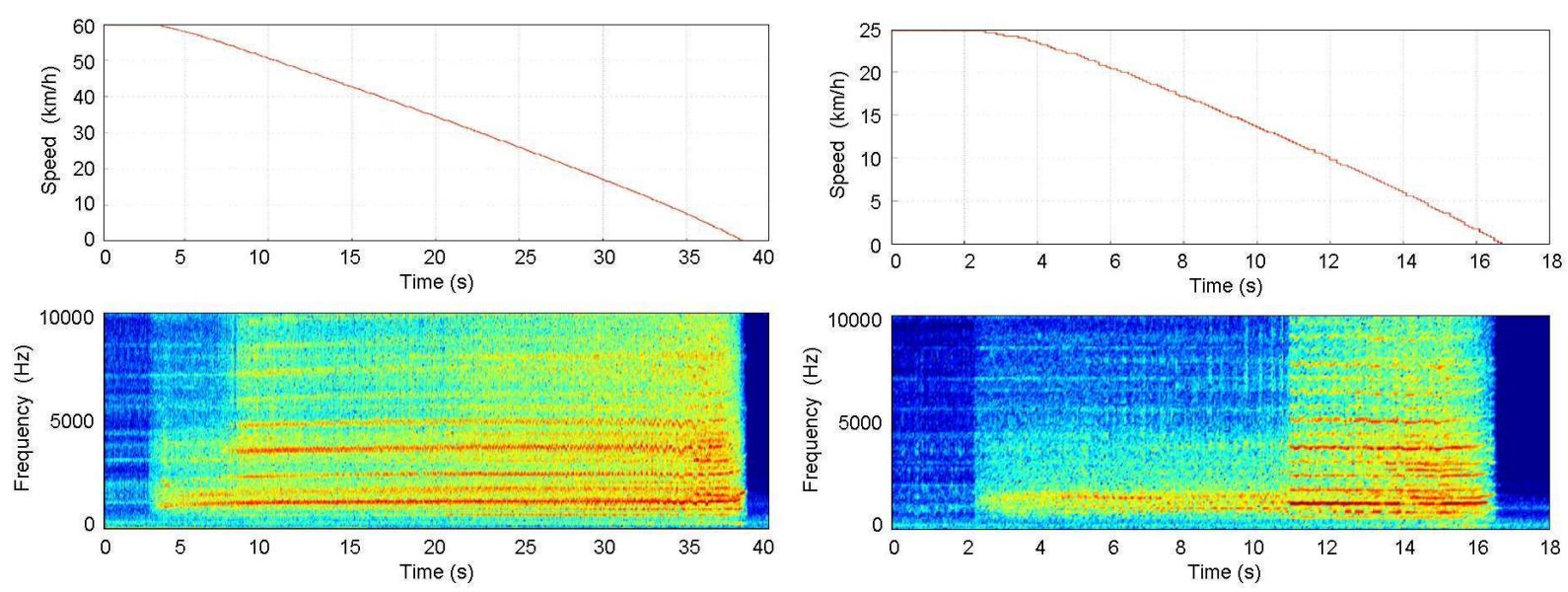

(c)

(d)

Figure 3: Evolution of the rotating speed of the disc and Continuous Wavelet Transform of experimental data with microphone measurement(a) $15 \mathrm{kN}-60 \mathrm{~km} / \mathrm{h}$ (b) $15 \mathrm{kN}-25 \mathrm{~km} / \mathrm{h}$ (c) $8 \mathrm{kN}-60 \mathrm{~km} / \mathrm{h}$ (d) $8 \mathrm{kN}-25 \mathrm{~km} / \mathrm{h}$

brake squeal appears to be globally the same for the four operating conditions, as indicated in Table 1: TGV brake squeal appears at low/middle frequency in the $0-10000 \mathrm{~Hz}$ range (with a predominant frequency content in the $0-5000 \mathrm{~Hz}$ range). For the first identified behavior of TGV squeal $(15 \mathrm{kN}-60 \mathrm{~km} / \mathrm{h}$ and $15 \mathrm{kN}-$ $25 \mathrm{~km} / \mathrm{h}$, see Figures 3(a) and (b)), only one characteristic dynamic behavior is identified. At the beginning of transient vibrations, an evolution and increase of the squeal frequencies is observed (see Figures $3(\mathrm{a})$ and (b) between $t=[3 ; 4] \mathrm{s}$ for $15 \mathrm{kN}-60 \mathrm{~km} / \mathrm{h}$, and $t=[2.5 ; 5] \mathrm{s}$ for $15 \mathrm{kN}-25 \mathrm{~km} / \mathrm{h}$ ). Moreover, it clearly appears that all the transient nonlinear oscillations can become complex with the contribution of several frequencies. For the second identified behavior of TGV squeal $(8 \mathrm{kN}-60 \mathrm{~km} / \mathrm{h}$ and $8 \mathrm{kN}-25 \mathrm{~km} / \mathrm{h}$, see Figures $3(\mathrm{c})$ and (d)), two dynamic behaviors are observed: firstly, a "simple" behavior of the transient oscillations with only frequency resonances around $1000-2000 \mathrm{~Hz}$ (see Figures $3(\mathrm{c}$ ) and (d) between $t=[2 ; 7] \mathrm{s}$ for $8 \mathrm{kN}-60 \mathrm{~km} / \mathrm{h}$, and $t=[2 ; 11] \mathrm{s}$ for $8 \mathrm{kN}-25 \mathrm{~km} / \mathrm{h}$ ); secondly, a "complex" nonlinear transient behavior with the appearances of new contributions in the $2000-10000 \mathrm{~Hz}$ range (see Figures $3(\mathrm{c})$ and (d) between $t=[7 ; 39] \mathrm{s}$ for $8 \mathrm{kN}-60 \mathrm{~km} / \mathrm{h}$, and $t=[11 ; 17] \mathrm{s}$ for $8 \mathrm{kN}-25 \mathrm{~km} / \mathrm{h})$. As explained in [21], evolution of the transient vibrations and the frequency content of the TGV brake squeal are governed by the modification of the sliding nonlinear equilibrium point (i.e. initial sliding position due to the compression force) during self-excited vibration. This may lead to new instabilities in the TGV brake system and induces a transition from one to the other behavior. For the interested reader, occurrences of squeal frequencies from the microphone and accelerometers on the backplate 

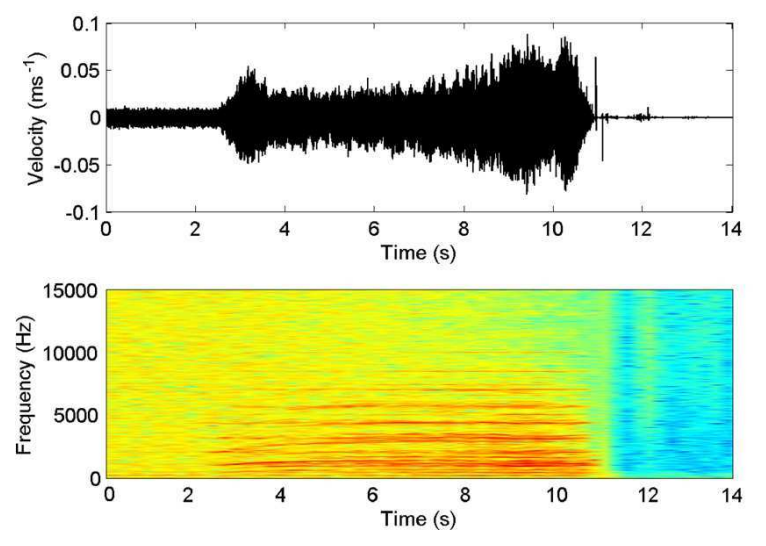

Figure 4: Time plot and wavelet power spectrum of experimental data for vibrometer measurement $(15 \mathrm{kN}-$ $25 \mathrm{~km} / \mathrm{h})$

of the TGV brake system are also characterize by specific frequencies ranging from $1000 \mathrm{~Hz}$ to $5000 \mathrm{~Hz}$, the most representative frequencies being located at $1200 \mathrm{~Hz}, 1700 \mathrm{~Hz}, 2150 \mathrm{~Hz}, 2500 \mathrm{~Hz}$ and $3400 \mathrm{~Hz}$.

\subsection{Controlled braking tests: experiments with a controlled steady speed}

The main purpose of this section is to correlate generation and characteristics of squeal noise via "controlled braking tests"(i.e. experiments with a controlled steady rotational speed of the disc) with the previous general observations made for transient braking tests.

Some of the results that will be presented in this section are now well known and established, but they are determinant and particularly important to propose and argue a rigorous methodology for modeling the squeal mechanism. In our case, we focus on the choice of whether or not to model the change in the rotating speed of the disc for squeal prediction. One must keep in mind that achieving a modeling of squeal generation for TGV brake system will be easier to implement and to solve if we can approximate the braking test by a problem of friction-induced vibration with a constant rotational speed of the TGV disc. If this assumption is not valid, it is not possible at present to make an accurate finite element model with computational simulations for predicting squeal noise due to the fact that computation time and data storage will not be possible if all the braking test must be simulated. Conversely, if we can simulate squeal noise by performing calculations around a sliding equilibrium point with constant operating conditions (and on a small time interval), the current capabilities of computers allow to conduct such studies.

The "controlled braking tests" are conducted as follows: the TGV disc is set in motion to a constant rotational speed with the disc and the pads out of contact. Then, all the pads are brought into contact with the disc (on each side of the disc) by maintaining the contact force to the desired value. This process allows to control better the conditions of occurrence of squeal and to avoid stick-slip occurring immediately if the disc rotating starts whereas the disc and pads are already in contact. As in previous tests (Section 2.3), care was taken to verify the repeatability of these controlled braking tests by performing three tests for each controlled speed cases. Moreover, special attention was paid to maintain an initial given temperature for each experiments.

These controlled braking tests will be performed for two compression forces $(8 \mathrm{kN}$ and $15 \mathrm{kN}$ as previously done for braking tests in Section 2.3) and two constant rotational speeds of the disc $(7 \mathrm{~km} / \mathrm{h}$ and $14 \mathrm{~km} / \mathrm{h})$. These two rotational speed of the disc $(7 \mathrm{~km} / \mathrm{h}$ and $14 \mathrm{~km} / \mathrm{h})$ have been chosen to be small enough to avoid a rapid degradation of the disc and pads during controlled braking tests while remaining realistic values to allow comparisons with TGV transient braking tests.

Figures 5 show the time plot of the normal velocity of the disc measured by the vibrometer for two operating conditions $(8 \mathrm{kN}-7 \mathrm{~km} / \mathrm{h}$ and $15 \mathrm{kN}-14 \mathrm{~km} / \mathrm{h})$. First of all, squeal occurs as soon as the disc and the pads are in contact and is still present during the test. Moreover, the squeal event appears to be stationary. 


\begin{tabular}{|c|c|c|c|c|c|c|c|c|c|c|c|}
\hline Tests & $\mathrm{n}^{\circ}$ & \multicolumn{10}{|c|}{ Frequency $(\mathrm{Hz})$} \\
\hline & & $\begin{array}{l}1200 \\
\pm 100\end{array}$ & $\begin{array}{l}1700 \\
\pm 100\end{array}$ & $\begin{array}{c}2150 \\
\pm 75\end{array}$ & $\begin{array}{l}2500 \\
\pm 50\end{array}$ & $\begin{array}{c}3400 \\
\pm 100\end{array}$ & $\begin{array}{l}3900 \\
\pm 50\end{array}$ & $\begin{array}{l}4600 \\
\pm 100\end{array}$ & 5800 & $\begin{array}{l}7150 \\
\pm 25\end{array}$ & 8500 \\
\hline $8 \mathrm{kN}$ & 1 & $\times$ & $x$ & $\times$ & $x$ & $x$ & $\times$ & & & & \\
\hline $25 \mathrm{~km} / \mathrm{h}$ & 2 & $x$ & $x$ & $x$ & $x$ & $x$ & $x$ & & & & \\
\hline $\operatorname{Rot}+$ & 3 & $x$ & $x$ & $x$ & $x$ & $x$ & & $x$ & & & \\
\hline $8 \mathrm{kN}$ & 1 & $x$ & $x$ & $\bar{x}$ & $\bar{x}$ & $x$ & $x$ & $x$ & $x$ & & \\
\hline $25 \mathrm{~km} / \mathrm{h}$ & 2 & $x$ & $x$ & $x$ & $x$ & $x$ & $x$ & & $x$ & $x$ & \\
\hline Rot- & 3 & $x$ & $x$ & $x$ & & $x$ & $x$ & & & & \\
\hline $8 \mathrm{kN}$ & 1 & $x$ & $\bar{x}$ & $\bar{x}$ & $x$ & $x$ & $x$ & $\times$ & $x$ & & \\
\hline $60 \mathrm{~km} / \mathrm{h}$ & 2 & $x$ & $x$ & $x$ & $x$ & $x$ & $x$ & & $x$ & $x$ & \\
\hline Rot + & 3 & $x$ & $x$ & $x$ & $x$ & $x$ & & & & & \\
\hline $8 \mathrm{kN}$ & 1 & $x$ & $x$ & $\bar{x}$ & & $x$ & $x$ & & & & \\
\hline $60 \mathrm{~km} / \mathrm{h}$ & 2 & $x$ & $x$ & & & $x$ & & & & $x$ & $x$ \\
\hline Rot- & 3 & $\times$ & $\times$ & $x$ & & $x$ & & & & $\times$ & $x$ \\
\hline $15 \mathrm{kN}$ & 1 & $x$ & $x$ & & & $x$ & & $x$ & & & \\
\hline $25 \mathrm{~km} / \mathrm{h}$ & 2 & $x$ & $x$ & & & & & & & & \\
\hline $\operatorname{Rot}+$ & 3 & $x$ & $x$ & & $x$ & $x$ & & $x$ & & & \\
\hline $15 \mathrm{kN}$ & 1 & $x$ & $\bar{x}$ & $x$ & & $x$ & & $x$ & & $x$ & \\
\hline $25 \mathrm{~km} / \mathrm{h}$ & 2 & $x$ & $x$ & $x$ & & $x$ & & $x$ & & $x$ & \\
\hline Rot- & 3 & $x$ & $x$ & $x$ & & $x$ & & $x$ & & $\times$ & \\
\hline $15 \mathrm{kN}$ & 1 & $x$ & $\bar{x}$ & $\bar{x}$ & & $x$ & & & & & \\
\hline $60 \mathrm{~km} / \mathrm{h}$ & 2 & $x$ & $x$ & $x$ & & $x$ & & & & & \\
\hline Rot + & 3 & $x$ & $x$ & & & $x$ & & & & & \\
\hline $15 \mathrm{kN}$ & 1 & $\bar{x}$ & $x$ & $x$ & & & & & & & \\
\hline $60 \mathrm{~km} / \mathrm{h}$ & 2 & $x$ & $x$ & $x$ & $x$ & $x$ & & $x$ & & $\times$ & \\
\hline Rot- & 3 & $\times$ & $\times$ & $\times$ & $\times$ & $\times$ & & $x$ & & & \\
\hline Occurrence (\%) & & 100 & 100 & 79 & 54 & 92 & 33 & 38 & 8 & 21 & 8 \\
\hline
\end{tabular}

Table 1: Experimental analysis of TGV brake system with occurrences of squeal frequencies (vibrometer)

For the two operating conditions, the squeal characterization in term of amplitudes and frequencies appears to be very similar. In addition, these results appear very close to the previous transient braking tests (see Figure 4). Amplitudes of the normal velocity are of the same order of magnitude: for the controlled braking test given in Figure 5(b) (operating conditions: $15 \mathrm{kN}-14 \mathrm{~km} / \mathrm{h}$ ), amplitudes of the normal velocity are around $0.05 \mathrm{~ms}^{-1}$; for the transient braking test given in Figure 4 (with the initial operating conditions: $15 \mathrm{kN}-25 \mathrm{~km} / \mathrm{h}$ ), the amplitudes are around $0.04 \mathrm{~ms}^{-1}$ at time $t=7 \mathrm{~s}$ (this time has been chosen due to the fact that it corresponds to the same rotational speed of the disc, $14 \mathrm{~km} / \mathrm{h}$, than that of the controlled braking test). Table 2 gives the frequency content for the two operating conditions. Comparing the transient and controlled braking tests, the frequency content appears to be also very similar for both experiments (transient braking tests given in Table 1 and controlled braking tests given in Table 2). Figure 6 gives a comparison of the frequency spectrum of the two signals for both the "controlled braking test" and "transient braking test". First of all, slight differences may be noticed. Some amplitude peaks are higher for the "controlled braking test" than for "transient braking test" (see for example peak magnitudes at $240 \mathrm{~Hz}, 5700 \mathrm{~Hz}, 7150 \mathrm{~Hz}$ and $8500 \mathrm{~Hz}$ ). Then, additional small peaks are visible for the "controlled braking test" for all the frequency range of interest. However, the peaks for the "transient braking test" are also found for the "controlled braking test". It should be noted that it is not trivial to reproduce exactly and consistently the magnitudes of squeal noise for braking tests (and so to perform comparisons between "controlled braking tests" and "transient braking tests") due to the fact that the transient normal velocity of braking test fluctuates slowly during 

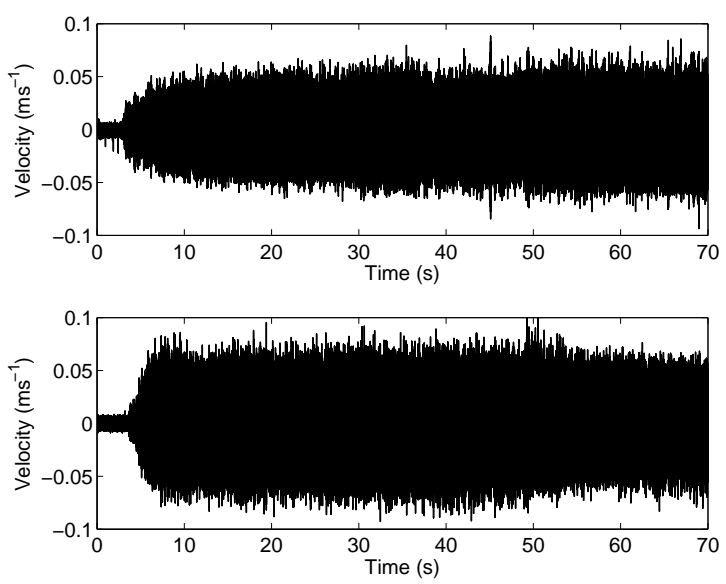

Figure 5: Time plot of experimental data for vibrometer measurement (upper figure: $8 \mathrm{kN}-7 \mathrm{~km} / \mathrm{h}$, lower figure: $15 \mathrm{kN}-14 \mathrm{~km} / \mathrm{h}$

time with decreasing of the rotational speed of the disc. For the interested reader, it can be noted that the difference between the two cases ("controlled braking test" and "transient braking test") in Figure 6 is larger than the variation within a given test case.

Then frequency content for different operating conditions $(15 \mathrm{kN}-7 \mathrm{~km} / \mathrm{h} ; 15 \mathrm{kN}-14 \mathrm{~km} / \mathrm{h} ; 8 \mathrm{kN}-7 \mathrm{~km} / \mathrm{h}$ and $8 \mathrm{kN}-14 \mathrm{~km} / \mathrm{h}$ with a positive rotation Rot + ) are given in Table 2 . The symbol $\times$ indicates the presence of the frequency. The variation (i.e. \pm bounds on the squeal frequencies) is between tests (for different operating conditions). Strong correlations between these controlled braking tests are observed: firstly, squeal noise appears when the disc and the pads come in contact without any change during the experimental tests. Then, squeal behavior is surprisingly repeatable and robust for various operating conditions: a proper understanding of the TGV brake squeal characterization is possible. By comparison with the previous "transient braking tests", the squeal characterization appears to be very similar. As indicated in Tables 1 and 2, TGV squeal noise appears at low/middle frequencies in the 0-10000 $\mathrm{Hz}$ range with a finite number of frequency peaks. The most repeatable frequency contributions are around $1700 \mathrm{~Hz}, 2150 \mathrm{~Hz}, 2500 \mathrm{~Hz}, 3400 \mathrm{~Hz}$, $3900 \mathrm{~Hz}$ and $4600 \mathrm{~Hz}$. It can also be noted that some extra frequencies (for example $240 \mathrm{~Hz}$ and $5200 \mathrm{~Hz}$, see Table 2) are indicated for the "controlled braking tests": these frequencies are also present in the "transient braking tests" (see Figure 6) but their contributions were small enough to be not reported in Table 1. Moreover it is recalled that variations of the squeal behavior were observed during time for transient braking tests (evolution of the squeal frequencies in Figure $3(\mathrm{a})$ for $15 \mathrm{kN}-60 \mathrm{~km} / \mathrm{h}$ and two separate characteristic behaviors during time in Figures 3(c) and (d) for $8 \mathrm{kN}-60 \mathrm{~km} / \mathrm{h}$ and $8 \mathrm{kN}-25 \mathrm{~km} / \mathrm{h}$ ). So the controlled braking tests can not exactly reproduced the transient braking tests.

In conclusion, the first obvious observation is that squeal can be the consequence of friction-induced vibration with a constant rotational speed of the disc. Moreover, we note a correlation (amplitudes and frequencies) between "transient braking tests" (experiments presented in Section 2.3) and "controlled braking tests"(experiments presented in Section 2.4): the dynamic behavior of squeal noise in industrial TGV railway brake system is characterize by specific frequencies ranging from $1000 \mathrm{~Hz}$ to $5000 \mathrm{~Hz}$. Secondly, the sufficient volume of data and the degree of repeatability of results allow us to consider these experimental results as a reference for validating the theoretical model of squeal prediction that will be discussed and developed in the next part of the paper. 


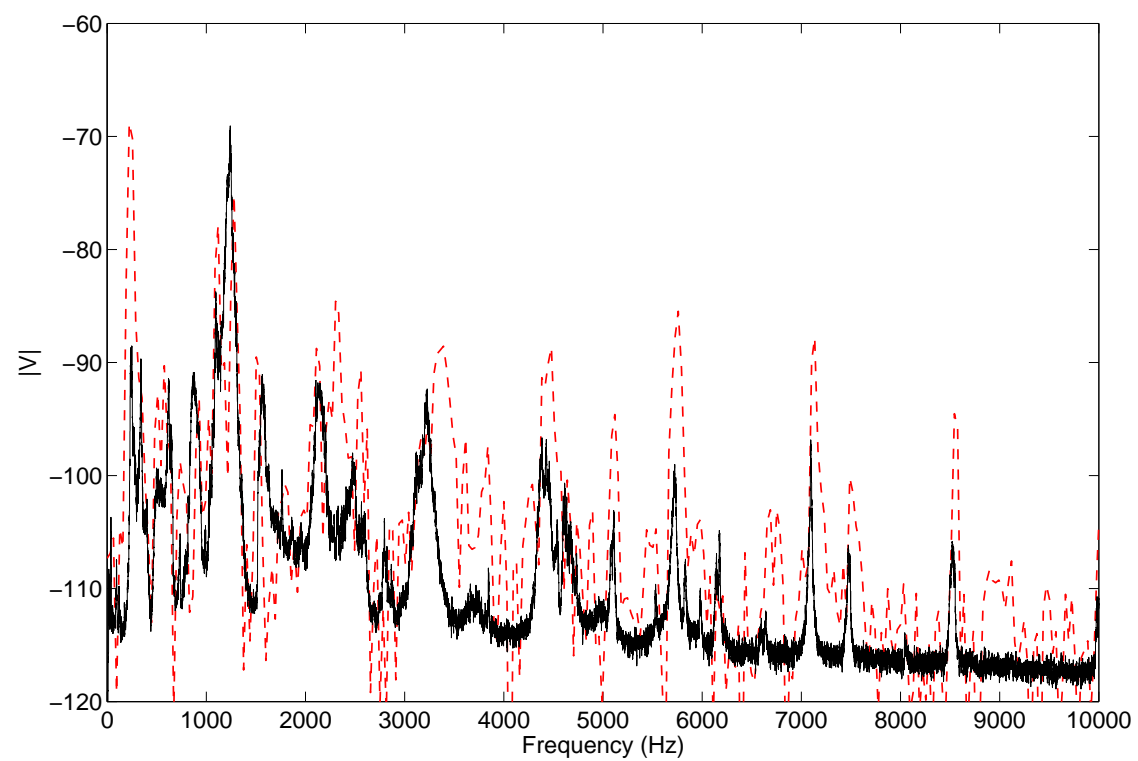

Figure 6: comparison of controlled braking test $(15 \mathrm{kN}-14 \mathrm{~km} / \mathrm{h})$ and transient braking test $(15 \mathrm{kN}-25 \mathrm{~km} / \mathrm{h})$ at $t=7 \mathrm{~s}$ for an equivalent rotating speed of $14 \mathrm{~km} / \mathrm{h}($ in $\mathrm{dB})$ (red lines = transient braking tests; dashed black lines $=$ controlled braking tests)

\begin{tabular}{|l|cccccccccccc|}
\hline Tests & \multicolumn{10}{|c|}{ Frequency (Hz) } \\
\hline & 240 & 1200 & 1700 & 2100 & 2600 & 3200 & 3900 & 4600 & 5200 & 5700 & 7100 & 8000 \\
& \pm 50 & \pm 150 & \pm 50 & \pm 100 & \pm 100 & \pm 100 & \pm 50 & \pm 100 & & & \\
\hline $\mathbf{8} \mathrm{kN}-\mathbf{7} \mathbf{k m} / \mathbf{h}$ & & $\times$ & $\times$ & $\times$ & $\times$ & & $\times$ & $\times$ & & & $\times$ & $\times$ \\
$\mathbf{8} \mathrm{kN}-\mathbf{1 4 k m} / \mathbf{h}$ & $\times$ & $\times$ & $\times$ & & $\times$ & $\times$ & $\times$ & & & & & \\
$\mathbf{1 5} \mathrm{kN}-\mathbf{7 k m} / \mathbf{h}$ & & $\times$ & $\times$ & $\times$ & & $\times$ & $\times$ & & & $\times$ & $\times$ & $\times$ \\
$\mathbf{1 5} \mathrm{kN}-\mathbf{1 4 k m} / \mathbf{h}$ & $\times$ & $\times$ & $\times$ & $\times$ & $\times$ & $\times$ & & $\times$ & $\times$ & & \\
\hline
\end{tabular}

Table 2: Experimental analysis of TGV brake system for squeal tests with constant speed

\section{Numerical simulation and comparison with experiments}

\subsection{TGV braking system and formulation of the problem}

The TGV brake system consists of one disc, outer and inner pads (18 pins applied on either sides of the disc are taken into account) modeled using the finite element method, as illustrated in Figure 7. The finite element model is composed of shell elements for the bell and quadratic volume elements for the disc and linings. The backplates and the supporting structure are modeled as rigid bodies with three spring elements taking into account the flexibility of the assembly. This simplification allows for containing the total number of degrees of freedom which is a necessary condition to perform full transient computations. Finally, the full finite element model has 72685 degrees of freedom (49473 degrees-of-freedom for the bell/disc system and 23212 degrees-of-freedom for all the lining). For the damping, a Rayleigh model is used with different coefficients for the disc and the pads. The non linear interface (i.e. the contact zone between the disc and the 18 pins) includes 504 pairs of nodes which represents a total of 3024 degrees of freedom. A Coulomb law with a constant friction coefficient $\mu$ is used. This formulation can be summarized as follow:

$$
\begin{aligned}
& \left\|\mathbf{r}_{\mathbf{t}}\right\| \leq-\mu r_{n} \\
& \left\|\mathbf{r}_{\mathbf{t}}\right\|=-\mu r_{n} \Rightarrow \exists \lambda \in \mathbb{R}^{+}, \dot{\mathbf{u}}_{\mathbf{t}}-\mathbf{v}_{\mathbf{g}}=-\lambda \mathbf{r}_{\mathbf{t}} \\
& \left\|\mathbf{r}_{\mathbf{t}}\right\|<-\mu r_{n} \Rightarrow \dot{\mathbf{u}}_{\mathbf{t}}-\mathbf{v}_{\mathbf{g}}=0
\end{aligned}
$$



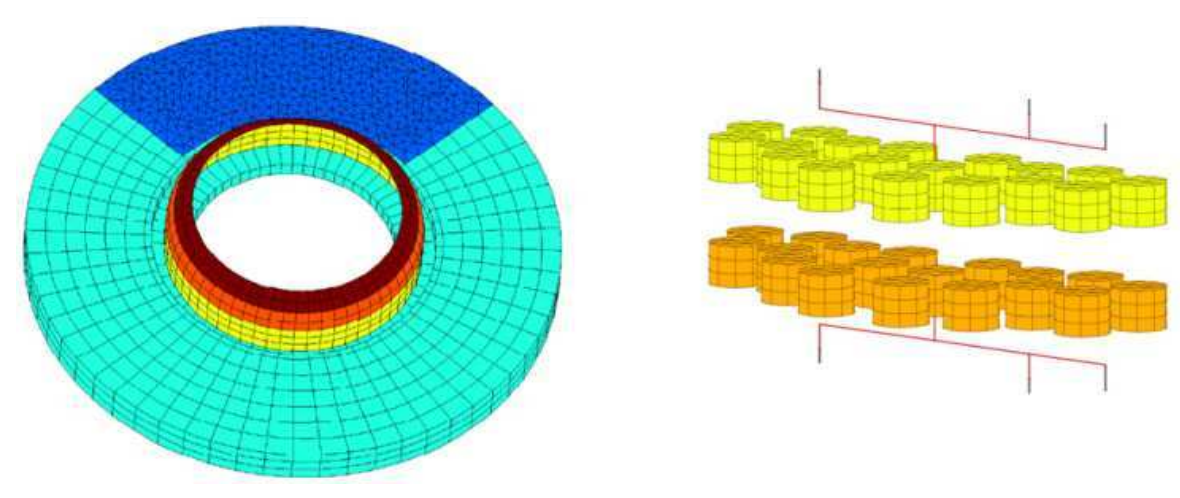

Figure 7: Finite element model of TGV brake system

where $\mathbf{r}$ is the contact reaction, $\mathbf{u}$ is the displacement field, $\mathbf{v}_{\mathbf{g}}$ is the Eulerian sliding speed. The subscripts $n$ and $t$ correspond to the normal and tangential projections of a field on the contact interface, respectively. Moreover, to deal with the unilateral contact, a non regularized Signorini law is chosen:

$$
u_{n}-g \leq 0 \quad ; \quad r_{n} \leq 0 \quad ; \quad\left(u_{n}-g\right) r_{n}=0
$$

where $g$ is the initial gap at the contact interface. The main advantage of the Signorini law results in the fact that it represents zero-penetration between surfaces : this is an interesting theoretical limit case equivalent to an infinite contact stiffness. In practice, it is assumed that the contact is sufficiently stiff so that the penetration may be neglected.

By using classical finite element discretization of the problem with linear elements on the potential contact zone leads, the nonlinear dynamics problem may be written in a discrete form as follows (see [22] for details):

$$
\mathbf{M} \ddot{\mathbf{u}}+\mathbf{C} \dot{\mathbf{u}}+\mathbf{K u}=\mathbf{f}+\mathbf{r}_{c}
$$

where $\mathbf{M}, \mathbf{K}$ and $\mathbf{C}$ are the classical mass, stiffness and damping matrices of the system. $\mathbf{f}$ and $\mathbf{r}_{c}$ define the generalized force and contact reaction respectively. The contact reaction $\mathbf{r}_{c}$, the displacement $\mathbf{u}$ and the velocity $\dot{\mathbf{u}}$ verify the contact and friction laws defined in equations (4) and (5) at each mesh node. Classically, a reformulation of these contact and friction laws can be rewritten in terms of projections on the negative real set $\left(\operatorname{proj}_{\mathbb{R}^{-}}\right)$and on the Coulomb cone $\left(\operatorname{proj}_{K_{\mu}}\right)$ is used to facilitate the numerical implementation in the treatment of the contact state [23]

$$
\begin{gathered}
r_{n}=\operatorname{proj}_{\mathbb{R}^{-}}\left(r_{n}-\rho_{n}^{u}\left(u_{n}-g\right)\right), \forall \rho_{n}^{u}>0 \quad \text { where } \operatorname{proj}_{\mathbb{R}^{-}}(x)=\min (x, 0) \\
\mathbf{r}_{\mathbf{t}}=\operatorname{proj}_{K_{\mu}}\left(\mathbf{r}-\rho_{t}\left(\mathbf{u}_{\mathbf{t}}-\mathbf{v}_{\mathbf{g}}\right)\right), \forall \rho_{t}>0 \quad \operatorname{with}_{\operatorname{proj}}{ }_{K_{\mu}}(\mathbf{x})=\left\{\begin{array}{c}
\mathbf{x}_{\mathbf{t}} \text { if }\left\|\mathbf{x}_{\mathbf{t}}\right\| /\left|x_{n}\right| \leq \mu \\
\mu \frac{\left|x_{n}\right|}{\left\|\mathbf{x}_{\mathbf{t}}\right\|} \mathbf{x}_{\mathbf{t}} \text { otherwise }
\end{array}\right.
\end{gathered}
$$

where $\rho_{n}^{u}$ and $\rho_{t}$ are two arbitrary positive scalars called normal displacement augmentation parameter and tangential augmentation parameter respectively. Considering equations (6-8), contact/no-contact and sticking/sliding events at each mesh node of the frictional interface can be simulated during transient simulations.

Before performing stability studies and a complete nonlinear analysis, validation of the finite element model for each component of the TGV brake system is performed by applying a classical modal analysis. There are two stages: firstly, we characterize the dynamics of the separate subsystems (disc, pads,backplate, support, etc) when the components are not in contact. This first configuration and these conditions are classically called "uncoupled subsystems and conditions". Then, characterization and validation of the finite element model are performed on the assembled components of the TGV brake system (conditions classically called "coupled system and conditions"). These first tests provide a reference behavior for the numerical model in correlation with experimental data. 


\subsection{Stability analysis of the TGV brake system}

In order to predict the occurrence of self-excited vibrations, a classical stability analysis can be performed. Complex eigenvalues and complex modes will be used to estimate the squeal propensity of the brake in a given frequency range $[3,24]$. This approach can be divided into two parts. The first step is the static problem: the steady-state operating point for the full set of nonlinear equations is obtained by solving them for the sliding equilibrium point. This sliding equilibrium point is obtained by solving the static equations for a given net brake pressure. Then, one obtains the linearized equations of motion by introducing small perturbations about the sliding equilibrium point into the nonlinear equations [3,21]. This leads to linearized contact laws (bilateral contact and sliding friction) applying only at contact nodes in the equilibrium position and given by :

$$
\begin{aligned}
& u_{n}=0 \\
& \mathbf{r}_{\mathbf{t}}=-\mu r_{n} \mathbf{t}+\mu \frac{r_{n}^{\mathrm{e}}}{v_{g}}(\dot{\mathbf{u}} \cdot \mathbf{b}) \mathbf{b}
\end{aligned}
$$

where $\mathbf{t}$ is the principal tangential direction given by the sliding velocity, $\mathbf{b}=\mathbf{n} \wedge \mathbf{t}$ is the second tangential direction (radial) and $r_{n}^{\mathrm{e}}$ is the static reaction force. Noting that the second term of the linearized friction force is equivalent to a contact radial damping, the eigenvalue problem to be solved is given by [22]

$$
\left(\lambda^{2} \tilde{\mathbf{M}}+\lambda \tilde{\mathbf{C}}+\tilde{\mathbf{K}}\right) \mathbf{u}_{\mathbf{0}}=\mathbf{0}
$$

with

$$
\begin{gathered}
\tilde{\mathbf{M}}=\mathbf{T}_{\mu}{ }^{\mathrm{T}} \mathbf{M} \mathbf{T}_{\mathbf{n}} \\
\tilde{\mathbf{K}}=\mathbf{T}_{\mu}{ }^{\mathrm{T}} \mathbf{K} \mathbf{T}_{\mathbf{n}} \\
\tilde{\mathbf{C}}=\mathbf{T}_{\mu}{ }^{\mathrm{T}}\left(\mathbf{C}-\mu \mathbf{P}_{\mathbf{b}}{ }^{\mathrm{T}} \mathbf{D} \mathbf{P}_{\mathbf{b}}\right) \mathbf{T}_{\mathbf{n}} \quad \text { with } \quad D_{i i}=\frac{\left(r_{n}^{\mathrm{e}}\right)_{i}}{\left(v_{g}\right)_{i}}
\end{gathered}
$$

where $\tilde{\mathbf{M}}, \tilde{\mathbf{C}}$ and $\tilde{\mathbf{K}}$ define the non-symmetric mass, damping and stiffness matrices. $\mathbf{T}_{\mathbf{n}}$ and $\mathbf{T}_{\mu}$ are the bases of the fields orthogonal to the normal $\mathbf{n}$ to the equilibrium contact interfaces (i.e. $u_{n}=0$ on the contact interfaces) and orthogonal to the direction $\mathbf{n}-\mu \mathbf{t}$ on the equilibrium contact interfaces (i.e. $\mathbf{u} \cdot(\mathbf{n}-\mu \mathbf{t})=0$ on the contact interfaces). The first projection matrix $\mathbf{T}_{\mathbf{n}}$ allows for a classical elimination of the displacements constraints whereas the second projection matrix $\mathbf{T}_{\mu}$ allows for an original elimination of the corresponding reactions in such a non symmetric problem. In addition, $\left(v_{g}\right)_{i}$ defines the norm of the sliding speed $\mathbf{v}_{\mathbf{g}}$ at the $i^{t h}$ node and $\mathbf{P}_{\mathbf{b}}$ corresponds to the projection matrix on the second tangential direction $\mathbf{b}$ at contact nodes. Then, stability consists on computing the complex modes and the complex eigenvalues associated to the linearized problem in the frequency range of interest (for more details see [22]). Solving this problem is achieved by using the Residual Iteration Method [25]. The complex eigenvalues $\lambda$ provide information about the local stability of the equilibrium point. The TGV brake system is stable if all the real part a of the eigenvalues are negative, and unstable if there exist one or more eigenvalues having a positive real part. The imaginary part of these eigenvalues represents frequencies of unstable complex modes that correspond to squeal frequencies.

First of all, the steady sliding equilibrium of the TGV brake system is given in Figure 8(a) for a friction coefficient of 0.35 : it is observed that this sliding position is not trivial with a more or less pronounced compression of pads. Moreover, the effects of the rotational direction of the disc can also be seen.

Then, the stability analysis of this equilibrium point is given in Figure 8(b) (for a friction coefficient of 0.35). This value has been chosen based on measurement (estimation based on squeal experiments of the previous sections). Nine unstable modes (with positive divergence rate) are detected. Figure 9 shows the mode shapes of these 9 unstable modes. Table 3 gives the frequency and growth rate for each unstable mode. The growth rate percentages is defined by $\frac{\operatorname{real}(\lambda)}{\operatorname{imag}(\lambda)}$ where $\lambda$ is the eigenvalue of interest. We can see that the modes with the most important growth rate appear from pads modes (near $2050 \mathrm{~Hz}$ and $2760 \mathrm{~Hz}$ with a growth rate of $9.47 \%$ and $6.44 \%$ respectively).

However, it is well known that computations via the complex eigenvalue problem (stability analysis) are not 


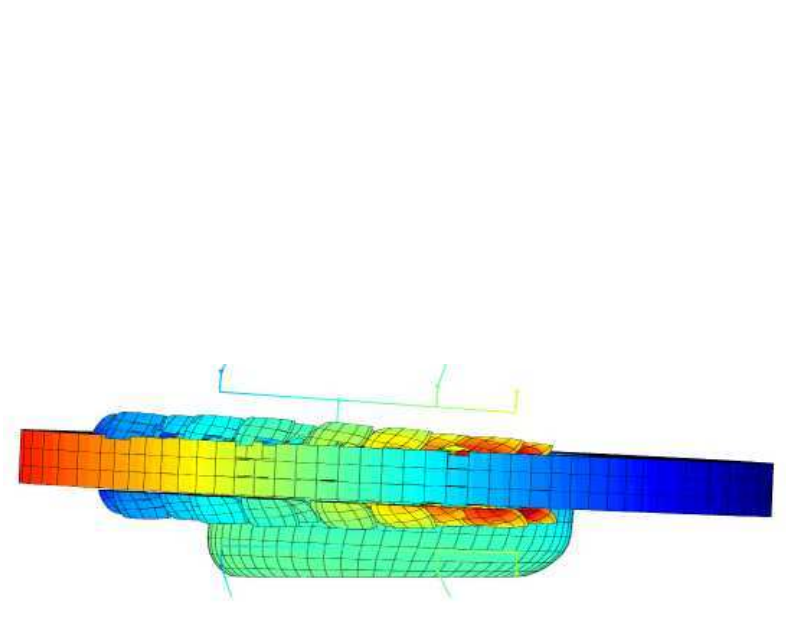

(a)

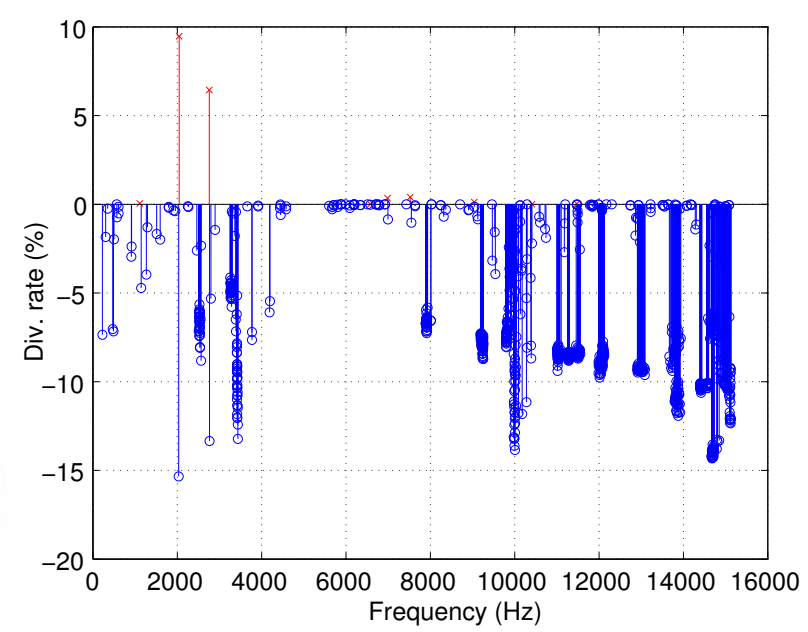

(b)

Figure 8: Stability analysis of the TGV brake system (a) Sliding equilibrium (b) Eigenvalues in the complex plane (red=unstable modes; blue=stable modes)

\begin{tabular}{ccc}
\hline Unstable Modes & Frequency $(\mathrm{Hz})$ & Divergence rate $(\%)$ \\
\hline 1 & 1110 & 0.047 \\
2 & 2050 & 9.47 \\
3 & 2760 & 6.442 \\
4 & 6580 & 0.006 \\
5 & 6980 & 0.344 \\
6 & 7530 & 0.403 \\
7 & 9050 & 0.122 \\
8 & 10410 & 0.0001 \\
9 & 11480 & 0.03 \\
\hline
\end{tabular}

Table 3: Frequency and growth rate of the unstable modes

sufficient to allow comparison between numerical tests and experiments. In fact, the stability considers only small regular perturbations without contact's break in the interface [21]. So frequencies of unstable complex modes may not correspond to squeal frequencies that have been observed during squeal experiments. So a complete nonlinear analysis of the transient and stationary nonlinear behaviors of the TGV brake system has to be undertaken if the fully developed behavior during squeal is of interest.

\subsection{Nonlinear self-excited vibrations}

As previously explained in [10,21], the stability analysis may lead to an underestimation or an over-estimation of the unstable modes observed in the nonlinear time simulation due to the fact that linear conditions (i.e. the linearized stability around an initial equilibrium point with a defined contact state for each node) are not valid during transient oscillations. So the nonlinear transient self-excited vibrations can become very complex and include more or less unstable modes due to the nonlinear contact and loss of contact interactions at the frictional interface. Therefore, a numerical resolution of the complete nonlinear system has to be performed in addition to the stability analysis to estimate the nonlinear behaviour of the solution far from the sliding equilibrium. Since the instability of the sliding equilibrium may lead to strongly nonlinear events with contact and no-contact states but also sticking and slipping states at the different frictional interfaces between each pad and the disc, a first-order $\theta$-method time integration scheme is developed for the computation of the 


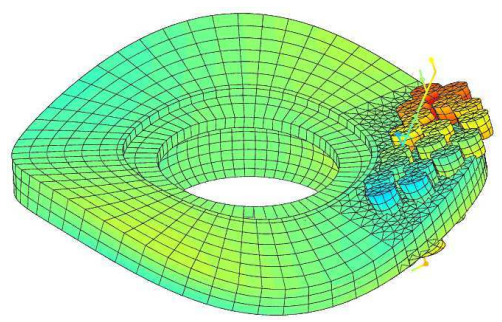

(a)

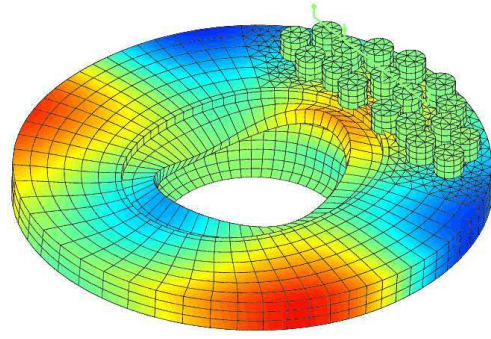

(d)

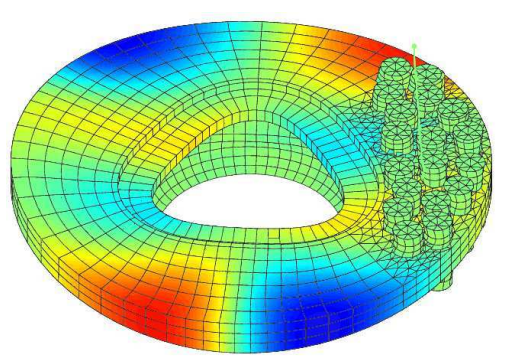

(g)

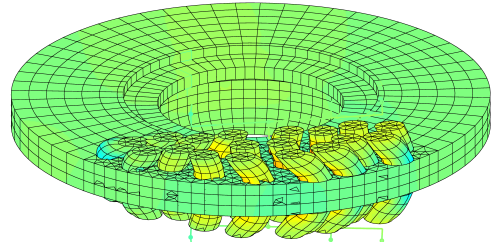

(b)

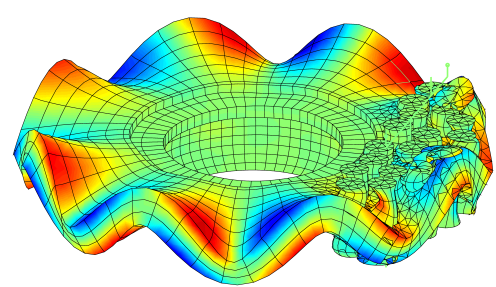

(e)

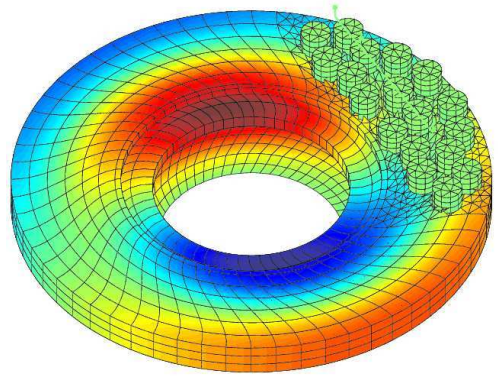

(h)

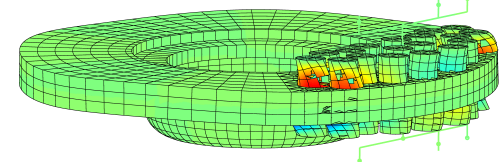

(c)

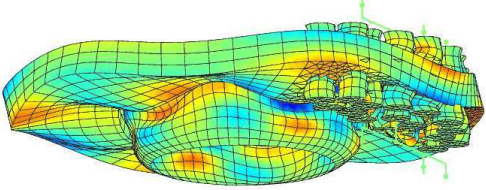

(f)

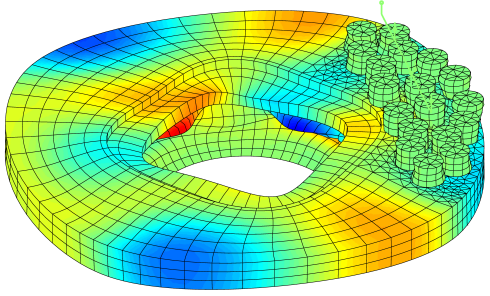

(i)

Figure 9: Mode shapes of the unstable modes (a) Mode 1, (b) Mode 2, (c) Mode 3, (d) Mode 4, (e) Mode 5, (f) Mode 6, (g) Mode 7, (h) Mode 8 and (i) Mode 9

transient solution. For more details, the interested reader is referred to the paper of Loyer et al. [22].

This next section of the paper is set up as follows: firstly, due to the size of the system and the extensive time of the nonlinear solving process, an efficient spatial model reduction is performed to estimate the nonlinear behavior of the TGV brake system. Secondly, comparisons between numerical results and experimental tests are investigated. The proposed reduction basis has been previously discussed and validated for the case of an elastic layer with a frictional interface [22]. The chosen basis is a classical modal truncated basis built from the real and imaginary parts of the complex stability modes (dynamic modes) with addition of constrained boundary modes at the contact interface (static modes). In the paper of Loyer et al. [22], this type of basis has been referred to as $F_{n}^{s}$ where $n$ is the number of modes included and $s$ corresponds to the inclusion of static modes in the reduction basis. In the present study, 1000 dynamic modes are kept in the reduced basis $\left(n=1000, F_{1000}^{s}\right)$ : this represents almost all the stability modes in the $[0-15] \mathrm{kHz}$ frequency range. This is a large number of modes but the frequency range of interest is also large $([0-10] \mathrm{kHz})$ and the modal density of the pads structure is rather high due to the number of pins. However, considering the initial number of degrees of freedom (72685), the reduced basis is in any case advantageous.

\subsubsection{Transient analysis of the TGV brake system}

Figure 10(a) illustrates the nonlinear transient solution of the velocity in the case of $\mu=0.35$. A succession of two phases is shown: the first one (for $t<0.01 \mathrm{~s}$ ) corresponds to a classical increase of the solution. The 
second one (for $t=[0.01 ; 0.11] \mathrm{s}$ ) is characterized by a global saturation with oscillations. Comparing the time-history computation and experiments that have been previously presented in Section 2 (see Figures 4 and 5), the level of stationary amplitudes is well reproduced.

In order to better analyze the evolution of the nonlinear transient behavior of the TGV brake system, Figure 10(b) expands the numerical transient solution on the basis of the complex modes. For the interested reader, the complex modal projection and formulation proposed in [2] are explained in detail by Loyer et al. [22]. Following the evolution of the modal participations allow us to evaluate the energy contribution of each mode during the transient response of the TGV brake system. This evolution of the modal participation $\beta_{j}(t)$ for the $j^{\text {th }}$ mode can be expressed by [22]

$$
\beta_{j}(t)=\frac{\boldsymbol{\Psi}_{\mathbf{0 j}_{\mathbf{j}}{ }^{\mathrm{T}} \tilde{\mathbf{A}} \boldsymbol{\Gamma}(t)}}{\boldsymbol{\Psi}_{\mathbf{0}_{\mathbf{j}}}{ }^{\mathrm{T}} \tilde{\mathbf{A}} \boldsymbol{\Phi}_{\mathbf{0}_{\mathbf{j}}}} \quad \text { with } \quad \tilde{\mathbf{A}}=\left[\begin{array}{cc}
\tilde{\mathbf{C}} & \tilde{\mathbf{M}} \\
\tilde{\mathbf{M}} & \mathbf{0}
\end{array}\right]
$$

where $\boldsymbol{\Gamma}(t)$ is the transient perturbation written in state-space variables (i.e. $\boldsymbol{\Gamma}=\left[\begin{array}{lll}\mathbf{u} & \dot{\mathbf{u}}\end{array}\right]^{\mathrm{T}}$ ). $\boldsymbol{\Phi}_{\mathbf{0} \mathbf{j}}$ and $\boldsymbol{\Psi}_{\mathbf{0} \mathbf{j}}$ define the modes shapes in state space and the adjoint mode shapes (with the bi-orthogonality relation $\forall i \neq j \quad \boldsymbol{\Psi}_{\mathbf{0} \mathbf{i}}{ }^{\mathrm{T}} \tilde{\mathbf{A}} \boldsymbol{\Phi}_{\mathbf{0} \mathbf{j}}=0$ and $\boldsymbol{\Psi}_{\mathbf{0} \mathbf{i}}{ }^{\mathrm{T}} \tilde{\mathbf{A}} \boldsymbol{\Phi}_{\mathbf{0} \mathbf{i}} \neq 0$ ). As previously explained by Loyer et al. [22], this complex modal projection allows detecting the contribution of one or more complex modes in the transient nonlinear

response. Moreover, the complex modal projection can be used to detect the appearance of limit cycles: when the nonlinear stationary response is reached, contributions of all the complex modal projections are constant or oscillate around an average value.

Showing the complex modal projection (see Figure 10(b)), the contribution of each unstable mode (that have been previously computed through the stability analysis) during the nonlinear transient and stationary solutions appears to be very clear. Two main zones are detected: for $t=[0 ; 0.01] \mathrm{s}$, a transition phase is observed with a fast increase of the contribution of modes 1, 2 and 3 (denoted M1, M2 and M3 respectively in Figure 10(b)). For $t>0.02 \mathrm{~s}$ the modal participation of all unstable modes fluctuates a little with a global signal suggesting that we have reached an approximately steady state solution. So it clearly appears that the modal participations of modes 4, 5, 6, 7, 8 and 9 remain a low level compared to the modal participations of modes 1, 2 and 3. In conclusion, the nonlinear response is mainly composed of the evolution of three principal modal participations. As previously explained in [22], the evolution of the system at the beginning of the time interval is governed by the complex modes (complex mode shapes and eigenvalues) obtained by the stability analysis computed around the sliding equilibrium point. Due to the fact that the "most unstable" modes for the stability analysis are modes 2 and 3 (i.e. the complex modes with the most important growth rates of $9.47 \%$ and $6.442 \%$ for modes 2 and 3, respectively), it is not surprising to find the modal participation of modes 2 and 3 in the first part of the transient response. Moreover, an increase of the contribution of mode 1 denoted M1 in Figure 10(b) can also be identified for $t=[0 ; 0.01] \mathrm{s}$ even if the stability analysis gives an initial growth rate of $0.047 \%$ for this "unstable" mode. This point will be more discussed in Appendix when evolutions of modal projections for the reduced model will be compared with those of the full original model.

\subsubsection{Nonlinear self-excited vibrations and comparison with experiments}

A typical brake squeal spectrum obtained via numerical simulations with the reduced basis is presented in Figure 11 and compared with measurements that have been discussed in Section 2.3 (see also Figure 4). While some features are recognizable there are also clearly some significant differences. First of all, some differences are observed in the frequency range $[0 ; 2500] \mathrm{Hz}$ : even if it is conceivable to correlate some experimental and numerical frequency peaks, it is clearly shown that the experimental frequency peaks are more distinct. Some similarities are also visible: for example, it can be distinguished two peaks around $3200 \mathrm{~Hz}$ and $4600 \mathrm{~Hz}$ for both experiments and numerical simulations. However, comparison of the peak amplitudes are not quite the same order of magnitude. Then, the global magnitudes and the frequency content and peak magnitudes appear to be more coherent between [500;10000]Hz. Even if a deviation of the frequency peaks are visible (around $5700 \mathrm{~Hz}, 6200 \mathrm{~Hz}, 7100 \mathrm{~Hz}, 7500 \mathrm{~Hz}$ and $8500 \mathrm{~Hz}$ ), an agreement between 


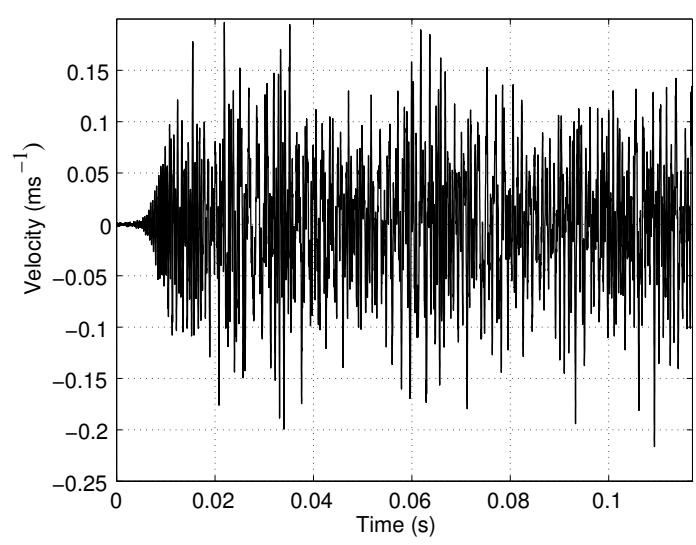

(a)

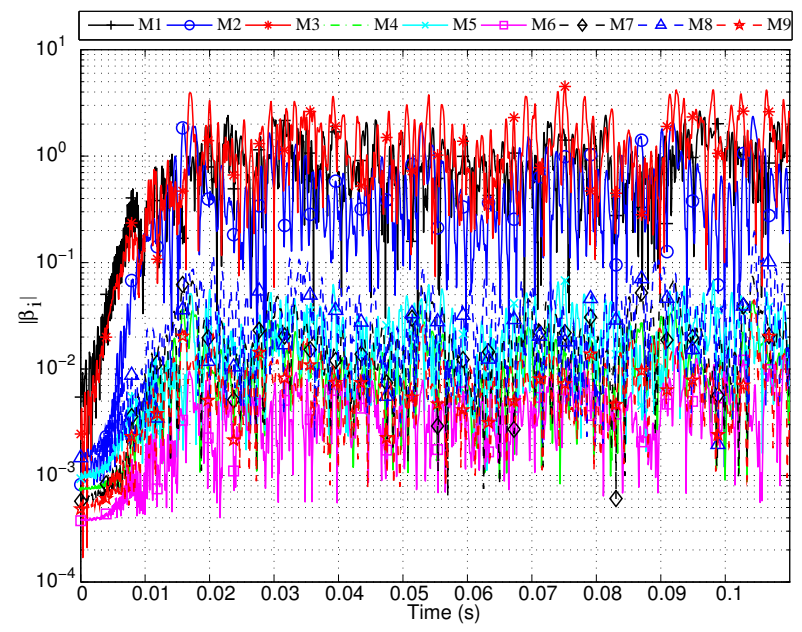

(b)

Figure 10: Transient analysis of the TGV brake system with reduced basis (a) Normal velocity and (b) complex modal projection where " $M_{i}$ " defines the $i^{\text {th }}$ unstable mode

experiment and numerical tests is found. So it may be concluded that comparisons show some similarities but also significant differences.

Finally, Figure 11 shows some frequency peaks that corresponds to the frequency of 'unstable modes" that have been previously predicted by the stability analysis: two peaks of significant magnitude around $1100 \mathrm{~Hz}$ and $2100 \mathrm{~Hz}$, and small peak amplitudes around $2700 \mathrm{~Hz}, 7000 \mathrm{~Hz}, 7500 \mathrm{~Hz}$ and $10000 \mathrm{~Hz}$. It is recalled that it has been shown that the modal projection of the first three modes (i.e. $1100 \mathrm{~Hz}, 2100 \mathrm{~Hz}$ and $2700 \mathrm{~Hz}$ ) is the most significant participations in the temporal signals (as indicated in Figure 10(b)). However, new frequency peaks (not previously predicted by the stability analysis) can appear in the signals, and so nonlinear transient amplitudes can become more complicated. For example, new resonance peaks are predicted near $3200 \mathrm{~Hz}, 4200 \mathrm{~Hz}$ and $5700 \mathrm{~Hz}$. They can correspond to the harmonic component or combination frequencies of fundamental frequencies: by defining $f_{1}=1100 \mathrm{~Hz}$ and $f_{2}=2100 \mathrm{~Hz}$ (i.e. the fundamental frequencies or the first and second unstable modes), the frequency $4200 \mathrm{~Hz}$ can be considered as the second harmonic component of the fundamental frequency $f_{2}$ (i.e. $2 f_{2}=4200 \mathrm{~Hz}$ ). The frequency $3200 \mathrm{~Hz}$ may correspond to the harmonic combinations $f_{1}+f_{2}$. These results clearly demonstrated the need to consider both stability and nonlinear analysis for undertaking transient nonlinear dynamic analysis of disc brake squeal: squeal events are composed of not only fundamental frequencies of unstable modes (i.e. eigenvalues via stability analysis) but also harmonic components and combination frequencies of several fundamental frequencies generally induced by nonlinear features of the vibrations. As previously explained in [21], these results show that the stability analysis of an sliding equilibrium point (classically used as the first step for frictioninduced vibration problem) only gives information about the initial rate of increase of TGV brake system's amplitudes. Due to nonlinear phenomena (in this case contact/no-contact) at the frictional interfaces over time, new frequencies can be added in the signals and so the nonlinear transient and stationary solutions can become more complicated.

\section{Conclusion}

First of all, this paper presents experimental analysis to understand the mechanism of TGV brake squeal. Two main experimental configurations were performed based on transient braking tests (braking for TGV industrial railway brakes by reducing the rotational speed of the disc) and controlled braking tests (i.e. braking for TGV industrial railway brakes with a constant rotational speed). It was demonstrated that experimental tests without decrease of the rotational speed of the disc is able to reproduce the major 


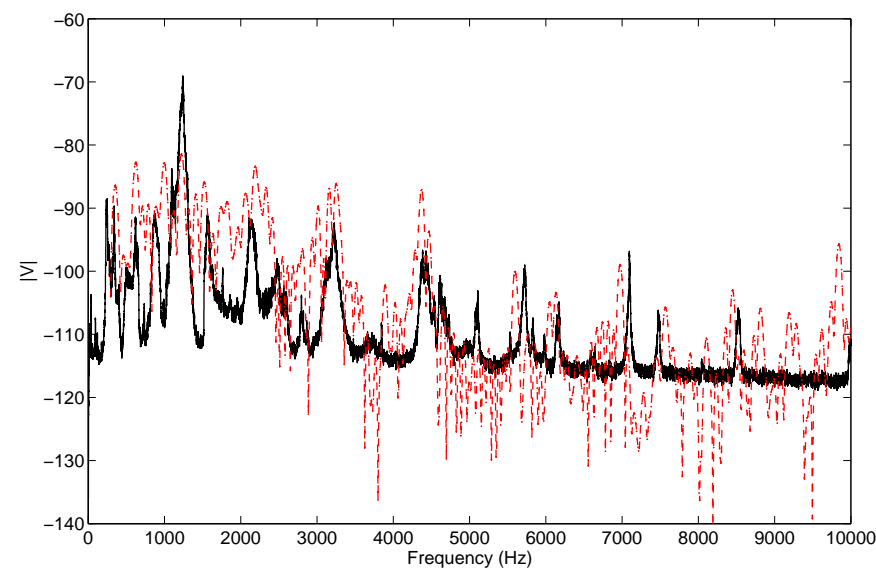

Figure 11: Comparisons of brake squeal spectrum via experimental and numerical approaches (in dB) (black lines $=$ experiments; dashed red lines $=$ reduced basis)

dynamics over short time-scales. Then, even if the phenomenon of squeal can be complex, experiments show that squeal can be clearly identified as the emergence of a finite number of frequencies regardless the operating conditions.

Secondly, a complete finite element model of TGV brake system has been developed to model vibration instabilities at the origin of disc brake squeal. Then, numerical methods dedicated to stability analysis, transient computations and reduction basis for industrial models have been proposed. Numerical results are in agreement with the experimental tests for the prediction of brake squeal.

Finally, it was demonstrated that not only the stability analysis but also the study of the transient-state behavior have to be performed to better predict and understand TGV disc brake squeal.

Future work to be considered consists of calculating the acoustic levels from transient self-excited vibrations and of defining new design of pads to reduce or eliminate self-excited vibrations on industrial railway brakes.

\section{Acknowledgments}

The authors gratefully acknowledge ADEME (Agence De l'Environnement et de la Maîtrise de l'Energie) who has partially funded this project AcouFren.

\section{References}

[1] X. Lorang, F. Foy-Margiocchi, Q.S. Nguyen, and P.E. Gautier. Tgv disc brake squeal. Journal of Sound and Vibration, 293:735-746, 2006.

[2] X. Lorang and O. Chiello. Stability and transient analysis in the modeling of railway disc brake squeal. Notes on Numerical Fluid mechanics and Multidisciplinary Design, 99:447-453, 2008.

[3] D. Brizard, O. Chiello, J-J. Sinou, and X. Lorang. Performances of some reduced bases for the stability analysis of a disc/pads system in sliding contact. Journal of Sound and Vibration, 330:703-720, 2011.

[4] R.A. Ibrahim. Friction-induced vibration, chatter, squeal and chaos: Part i-mechanics of contact and friction. ASME Applied Mechanics Review, 47(7):209-226, 1994.

[5] N.M. Kinkaid, O.M. O'Reilly, and P. Papadopoulos. Automotive disc brake squeal. ASME Applied Mechanics Review, 267:105-166, 2003. 
[6] H. Ouyang, N. Nack, Y. Yuan, and F. Chen. Numerical analysis of automotive disc brake squeal: a review. International Journal of Vehicle Noise and Vibration, 1:207-231, 2005.

[7] J-J. Sinou, F. Thouverez, and L. Jezequel. Methods to reduce nonlinear mechanical systems for instability computation. Archives of Computational Methods in Engineering: State of the Art Reviews, 11(3):257-344, 2004.

[8] S. Oberst and J.C.S. Lai. Chaos in brake squeal noise. Journal of Sound and Vibration, 330(5):955 975, 2011.

[9] S. Oberst and J.C.S. Lai. Statistical analysis of brake squeal noise. Journal of Sound and Vibration, 330(12):2978 - 2994, 2011.

[10] F. Chevillot, J-J. Sinou, and N. Hardouin. Nonlinear transient vibrations and coexistences of multi instabilities caused by friction in an aircraft braking system. Journal of Sound and Vibration, 328(45):555-574, 2009.

[11] F. Chevillot, J-J. Sinou, N. Hardouin, and L. Jézéquel. Simulations and experiments of a nonlinear aircraft braking system with physical dispersion. Journal of Vibration and Acoustics, 132(4):n041010, 2010 .

[12] T. Butlin and J. Woodhouse. Friction-induced vibration: Quantifying sensitivity and uncertainty. Journal of Sound and Vibration, 329(5):509 - 526, 2010.

[13] T. Butlin and J. Woodhouse. A systematic experimental study of squeal initiation. Journal of Sound and Vibration, 330(21):5077 - 5095, 2011.

[14] T. Butlin and J. Woodhouse. Sensitivity of friction-induced vibration in idealised systems. Journal of Sound and Vibration, 319(1-2):182 - 198, 2009.

[15] A. Akay, O. Giannini, F. Massi, and A. Sestieri. Disc brake squeal characterization through simplified test rigs. Mechanical Systems and Signal Processing, 23(8):2590 - 2607, 2009.

[16] R.Fagiani, F. Massi, E. Chatelet, Y. Berthier, and A. Akay. Tactile perception by friction induced vibrations. Tribology International, 44(10):1100 - 1110, 2011.

[17] O. Giannini, A. Akay, and F. Massi. Experimental analysis of brake squeal noise on a laboratory brake setup. Journal of Sound and Vibration, 292(1-2):1 - 20, 2006.

[18] O. Giannini and F. Massi. Characterization of the high-frequency squeal on a laboratory brake setup. Journal of Sound and Vibration, 310(1-2):394 - 408, 2008.

[19] F. Massi, L. Baillet, O. Giannini, and A. Sestieri. Brake squeal: Linear and nonlinear numerical approaches. Mechanical Systems and Signal Processing, 21(6):2374 - 2393, 2007.

[20] D. Newland. Wavelet analysis of vibration. part 1: theory. Journal of Sound and Vibration, 116:409416, 1994.

[21] J-J. Sinou. Transient nonlinear dynamic analysis of automotive disc brake squeal - on the need to consider both stability and nonlinear analysis. Mechanics Research Communications, 37:96-105, 2010.

[22] A. Loyer, J-J. Sinou, O. Chiello, and X. Lorang. Study of nonlinear behaviors and modal reductions for friction destabilized systems. application to an elastic layer. Journal of Sound and Vibration, 331(5):1011-1041, 2012.

[23] M. Jean. The non-smooth contact dynamics method. Computer Methods in Applied Mechanics and Engineering, 177(3-4):235-257, 1999. 
[24] H. Festjens, G. Chevalier, F. Renaud, J-L. Dion, and R. Lemaire. Effectiveness of multilayer viscoelastic insulators to prevent occurrences of brake squeal: a numerical study. Applied Acoustics, 73(11):11211128, 2012.

[25] A. Bobillot and E. Balmes. Iterative computation of modal sensitivities. American Institute of Aeronautics and Astronautics Journal, 44:1332-1338, 2006.

\section{Appendix: Comparison between the full and reduced models}

In this appendix, the efficiency and limitation of the reduced model will be investigated by comparing evolution of the modal participations for the full model and the reduced basis.

First of all, Figure 12 shows velocity of the TGV brake system for the full model. We can see that the proposed basis $F_{1000}^{s}$ gives good results comparing with the full model according to amplitudes of velocity. The computation time for the full model is approximately 20 days. The reduced basis used allows dividing by 6 times computation compared to the full model.

In order to validate the efficiency of the reduced basis, comparisons between the reduced and full models are given in Figures 13 and 14(a) and (b) for the three most important modal participations $\left(\beta_{1}(t), \beta_{2}(t)\right.$ and $\left.\beta_{3}(t)\right)$ and the others $\left(\beta_{4}(t), \beta_{5}(t), \beta_{6}(t), \beta_{7}(t), \beta_{8}(t)\right.$ and $\left.\beta_{9}(t)\right)$, respectively. It can be observed that evolution of these modal participations $\beta_{j}(t)$ for the reduced model is also in agreement with the reference solution (that is given by the full model): an increase of the modal contributions of modes 1,2 and 3 are observed in the first transient part of the solution (for $t=[0 ; 0.01] \mathrm{s}$ ).

Showing Figure 13, it can be seen that during the first transition phase (for $t=[0 ; 0.01] \mathrm{s}$ ), evolutions of the modal participations $\beta_{1}, \beta_{2}$ and $\beta_{3}$ are not exactly identical for the original full model and the reduced basis. More specifically, for $t=[0 ; 0.01] s$, the initial growth rate of mode 1 (denoted $\left|\beta_{1}\right|$ in Figure 13) is a little overestimated by the reduced model whereas the initial growth rate of mode 2 (denoted $\left|\beta_{2}\right|$ in Figure 13) is a little underestimated. This alteration of the transient evolution of modal participations in the temporal solution has been previously observed by Loyer et al. [22]. This fact may be due to an over or under estimation of the growth rate instability with the reduced basis: reduction can lead to accelerating or decelerating the evolution of the solution during the transient phase. For $t>0.01 \mathrm{~s}$, a good agreement is observed between the reduced case and the reference: evolutions of the three modal participations $\beta_{1}$, $\beta_{2}$ and $\beta_{3}$ are of the same order of magnitude for both cases. Finally, the evolutions of the other modal participations for the reduced case $\left(\beta_{4}(t), \beta_{5}(t), \beta_{6}(t), \beta_{7}(t), \beta_{8}(t)\right.$ and $\left.\beta_{9}(t)\right)$ are also in agreement with those of the full model, as illustrated in Figure 14(a) and (b).

As previously explained in Section 3.3.1, the evolution of the system at the beginning of the time interval is governed by the complex modes (complex mode shapes and eigenvalues) obtained by the stability analysis computed around the sliding equilibrium point. So modes 2 and 3 that are the "most unstable" modes (i.e. the complex modes with the most important growth rates) are predominant. The small increase of the contribution of mode 1 is also consistent with the stability analysis: the slow rate can be due to the small initial growth rate for mode 1 (i.e. $0.047 \%$ ). This observation shows the limitation of the basis reduction: even if the reduce base is adequate to reproduce the global nonlinear behavior of TGV brake system, some differences in the evolution of the most important modal contributions remain.

Finally, Figure 15 gives the brake squeal spectrum obtained via numerical simulations (for both the full model ) and a comparison with experimental results that have been discussed in Section 2.3. Even if some similarities are shown (frequency peaks and amplitudes at $3200 \mathrm{~Hz}, 4500 \mathrm{~Hz}$ and $7400 \mathrm{~Hz}$ but also around $7100 \mathrm{~Hz}$ and $8500 \mathrm{~Hz}$ with a slight deviation in frequency), some differences are still visible in the frequency range $[0 ; 2500] \mathrm{Hz}$.

These results show that we must remain cautious if full or reduced models are used for estimation of limit cycles amplitudes. It also opens up future prospects for the construction of full or reduced bases even more relevant to estimate not only the overall behavior but also the evolution in time of each modal participations. 


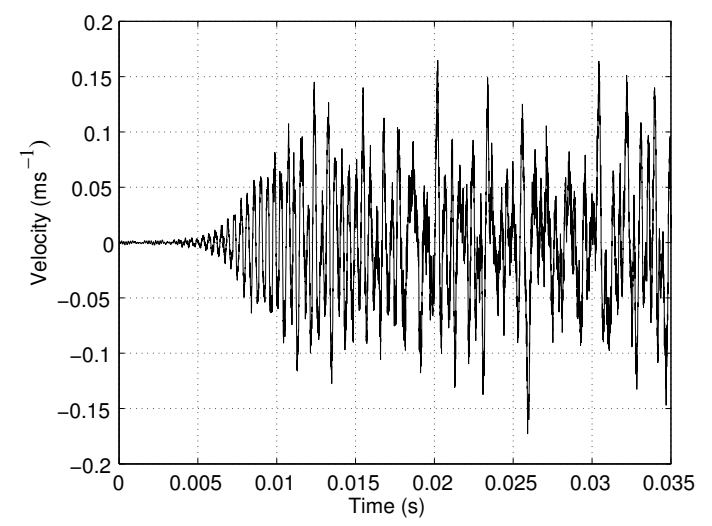

Figure 12: Normal velocity of the transient analysis for the full model
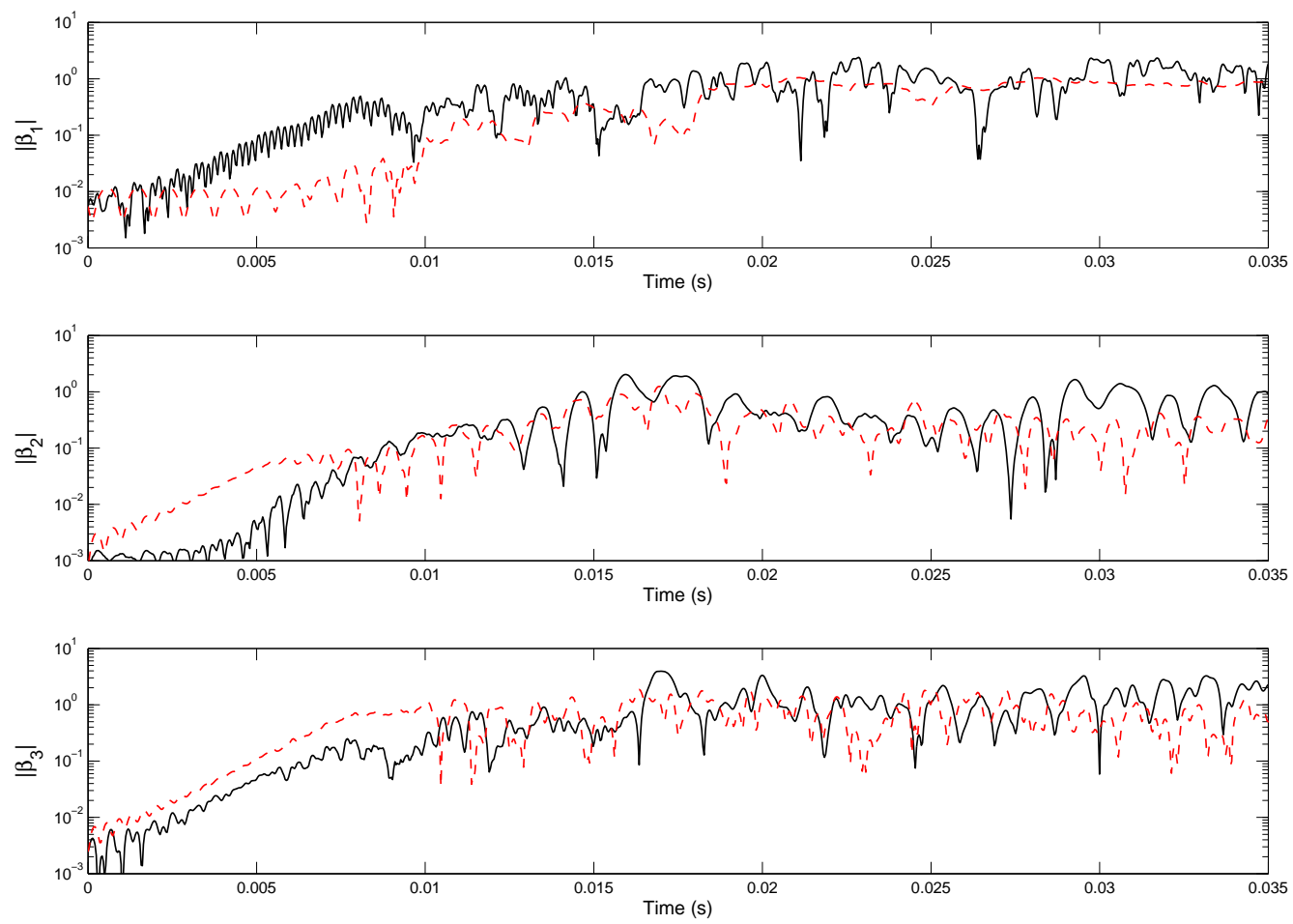

Figure 13: Comparisons of the complex modal projections $\beta_{1}, \beta_{2}$ and $\beta_{3}$ for the reference and the reduced basis (black lines $=$ reduced basis ; dashed red lines $=$ reference) 

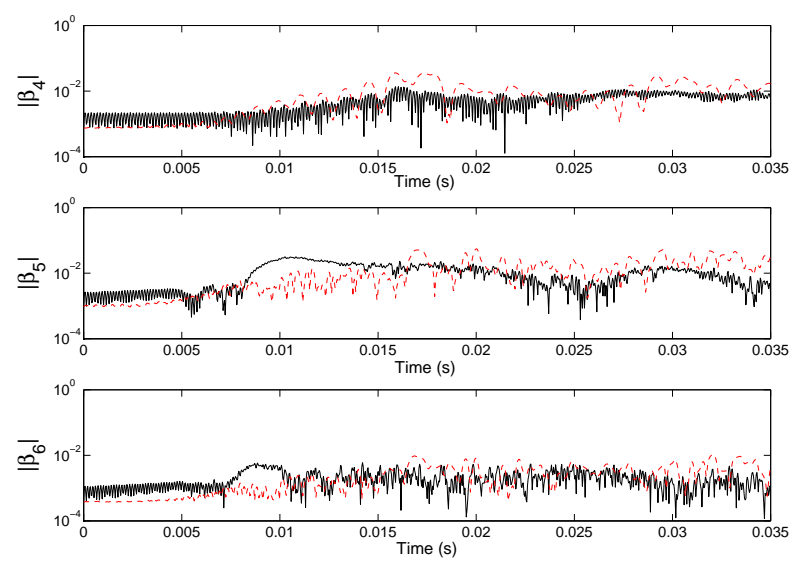

(a)
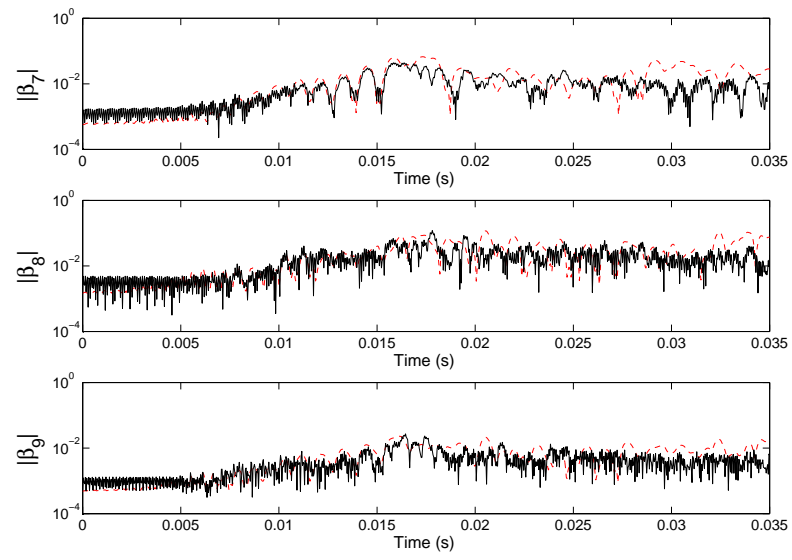

(b)

Figure 14: Comparison of the complex modal projection for the reference and the reduced basis (black lines $=$ reduced basis $;$ dashed red lines $=$ reference $)(\mathrm{a}) \beta_{4}(t), \beta_{5}(t)$ and $\beta_{6}(t) ;(\mathrm{b}) \beta_{7}(t), \beta_{8}(t)$ and $\beta_{9}(t)$

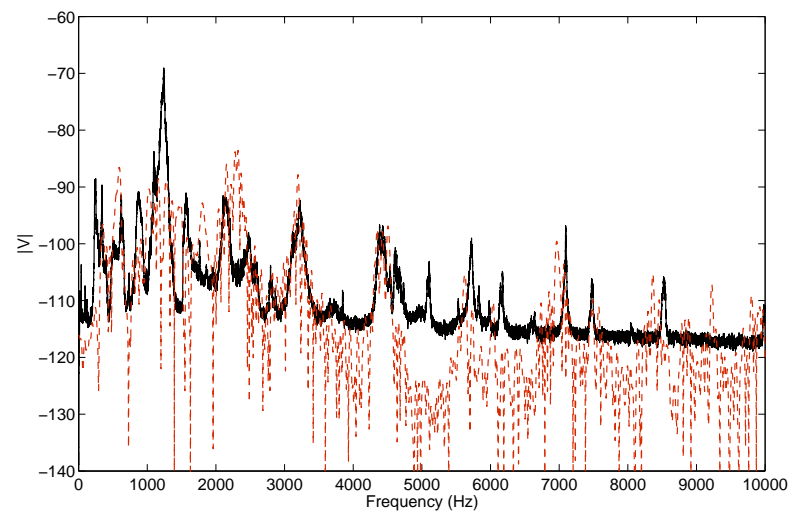

Figure 15: Comparisons of brake squeal spectrum via experimental and numerical approaches (in dB) (black lines $=$ experiments; dashed red lines $=$ full model) 